\title{
The Mass Difference Measurement of $\left({ }^{12} \mathrm{C}_{2}{ }^{1} \mathrm{H}_{4}-{ }^{12} \mathrm{C}^{16} \mathrm{O}\right)$, $\left({ }^{12} \mathrm{C}_{2}{ }^{1} \mathrm{H}_{4}{ }^{-14} \mathrm{~N}_{2}\right),\left({ }^{14} \mathrm{~N}_{2}-{ }^{12} \mathrm{C}^{16} \mathrm{O}\right)$ and $\left({ }^{12} \mathrm{C}_{2}{ }^{1} \mathrm{H}_{4}{ }^{-12} \mathrm{C}_{2}{ }^{2} \mathrm{D}_{2}\right)$
}

\section{Doublets}

\author{
H. Nakabushi, I. Katakuse AND K. Ogata*
}

(Received July 26 1969)

\begin{abstract}
The mass differencés of $\left(\mathrm{C}_{2} \mathrm{H}_{4}-\mathrm{CO}\right),\left(\mathrm{C}_{2} \mathrm{H}_{4}-\mathrm{N}_{2}\right),\left(\mathrm{N}_{2}-\mathrm{CO}\right)$ and $\left(\mathrm{C}_{2} \mathrm{H}_{4}-\mathrm{C}_{2} \mathrm{D}_{2}\right)$ doublets have been measured. The apparatus used is the reconstructed large mass spectroscope of double focusing type with the cylindrical electric field $\left(\phi_{e}=84^{\circ} 50^{\prime}, \mathrm{a}_{e}=1092 \mathrm{~mm}\right.$ ) and the uniform magnetic field ( $\phi_{m}$ $=60^{\circ}, \mathrm{a}_{m}=1200 \mathrm{~mm}$ ). The dimensions of main parts of this apparatus are quite similar to the old one destroyed by the high-tide typhoon in 1961 .

The half-width resolution of about 300,000 is obtained at routine operating condition (the slit. width of about $0.01 \mathrm{~mm}$ for both main and detector slits). The stabilizing circuits were inserted in the power sources of both the electro-static analyzer and the magnetic one, and the emission stabilizer in the ion source circuit. As the result, the drift of ion beam is reduced to a. few parts in $10^{7}$ per minute, and the good reproducibility of the operation is obtained.

Under such operating conditions, the measurements of $\left(\mathrm{C}_{2} \mathrm{H}_{4}-\mathrm{CO}\right),\left(\mathrm{C}_{2} \mathrm{H}_{4}-\mathrm{N}_{2}\right)$ and $\left(\mathrm{N}_{2}-\mathrm{CO}\right)$ doublet mass differences were performed with the visual orthodox peak matching method. by changing the measuring procedures which may be the causes of systematic errors. On the way of the measurements, a considerable large systematic error was found. This error came from the exciting current of the switching relay coil used for the peak matching. The estimations of the magnitudes of expected systematic errors were done. Moreover, using the closure error of the triplet derived from the mass differences of the above mentioned doublets, the correction factor for the measured values was calculated, and the mass differences corrected by this factor are adopted as the most reliable values. Finally, the doublet mass difference of $\left(\mathrm{C}_{2} \mathrm{H}_{4}-\mathrm{C}_{2} \mathrm{D}_{2}\right)$ was measured.
\end{abstract}

\section{Introduction}

In order to determine the atomic masses within the accuracy of a few parts in $10^{8}$, the conclusive investigations for systematic errors, which may be included in the values obtained, are the most important and essential ones. However, in general, such works are very difficult and tedious, and have not yet been done so throughly and system. atically. Since several years ago, some results on atomic masses having the accuracy above mentioned have been reported. ${ }^{1,2,3,4,5)}$ But they are not in so good agreement with each other, even they are measured at the same labora- tory. Under such present status of the precise atomic mass measurement, the main scope of present work is in finding out systematic errors and eliminating them as much as possible.

The instrument used here is the reconstructed large mass spectroscope of double focusing type with a cylindrical electric field $\left(\phi_{e}=84^{\circ} 50^{\prime}, \mathrm{a}_{e}=1092 \mathrm{~mm}\right.$ ) and an uniform magnetic field $\left(\phi_{m}=60^{\circ}\right.$, $\left.\mathbf{a}_{m}=1200 \mathrm{~mm}\right)$. The dimensions of main parts of this instrument are the quite similar to the old machine destroyed by the high-tide typhoon in 1961, but some developments were made for the effective areas of both the electric field

* Department of Physics, Faculty of Science, Osaka University(Toyonaka-shi, Osaka-fu, Japan) 
H. Nakabushi, I. Katakuse and K. Ogata

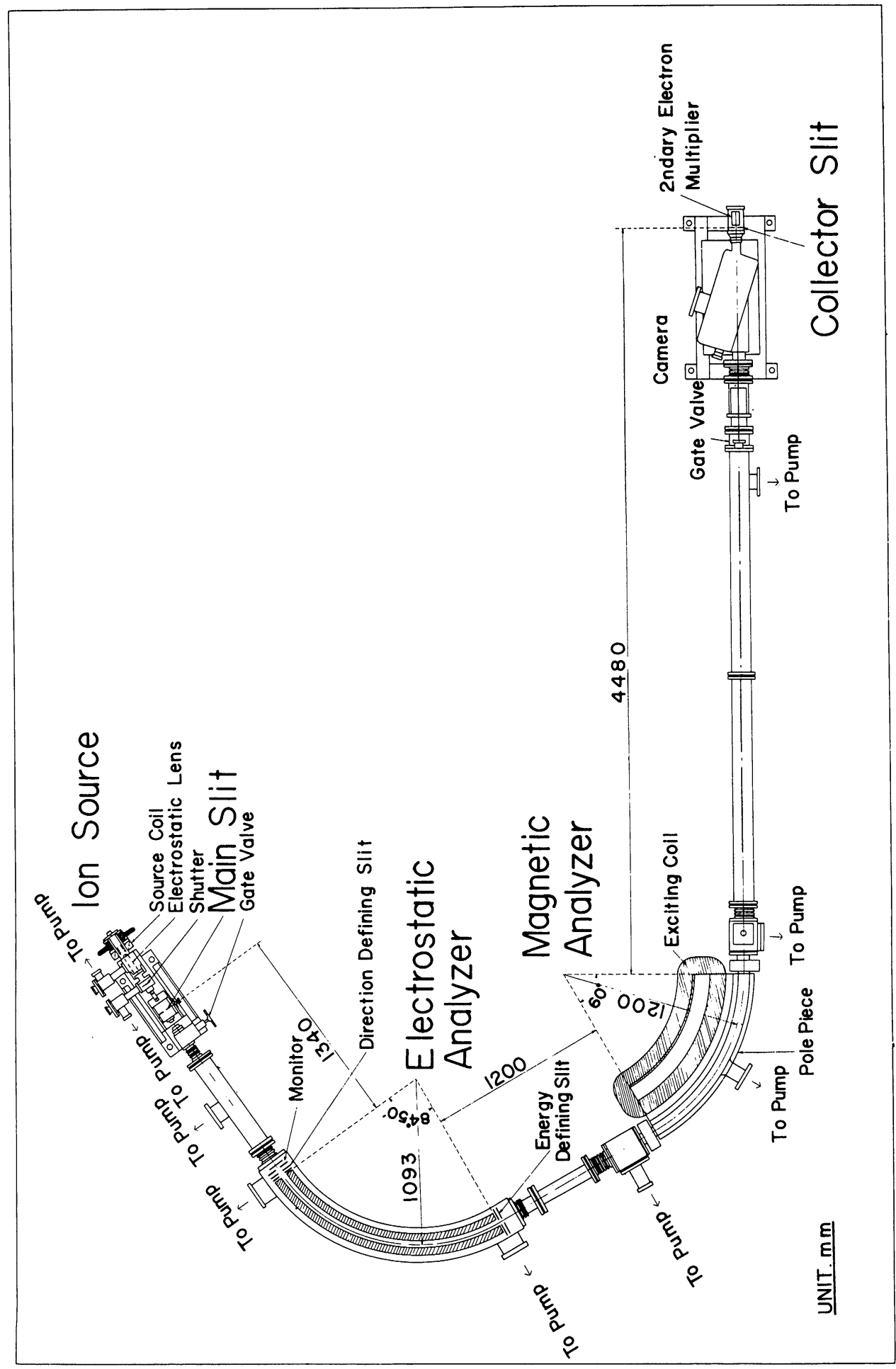

Fig. 1 Schematic diagram of the instrument 
Mass Differences; $\left(\mathrm{C}_{2} \mathrm{H}_{4}-\mathrm{CO}\right),\left(\mathrm{C}_{2} \mathrm{H}_{4}-\mathrm{N}_{2}\right),\left(\mathrm{N}_{2}-\mathrm{CO}\right)$ and $\left(\mathrm{C}_{2} \mathrm{H}_{4}-\mathrm{C}_{2} \mathrm{D}_{2}\right)$

and the magnetic one and for vacuum envelope materials, in order to increase the focusing stability.

And, as the measuring method for doublet mass differences, both the photographic method and the electrical one can be available for the new machine. The reason for introducing the above both measuring systems is as follows; in order to find out the unexpected systematic errors, it may be quite necessary to measure the doublet mass differences with the different methods using the same instrument.

As previously reported, ${ }^{6)}$ after the reconstructing and setting up works of the present machine were finished, the photographic method had been carried out for focus adjustment. And, the defocusing effect, of which cause could not be found out, was not overcome. So, for investigating this defocusing more throughly, the photographic method was replaced by the electric one, and immediately the following fact was found; such defocusing effect was mainly caused by the a. c. stray magnetic field filled in the room. After eliminating this cause of defocusing as much as possible, the fine focus adjustment was carried out and the base resolution of about 150,000 was obtained at routine operating condition (the slit width of about $0.01 \mathrm{~mm}$ for both main and detection slits).

Under the above operating condi tion, the measurements of $\left(\mathrm{N}_{2}-\mathrm{CO}\right)$, $\left(\mathrm{C}_{2} \mathrm{H}_{4}-\mathrm{N}_{2}\right)$ and $\left(\mathrm{C}_{2} \mathrm{H}_{4}-\mathrm{CO}\right)$ doublet mass differences were performed with the orthodox peak matching method by changing the measuring procedures, which may be the causes of systematic errors. On the way of the measurements, a considerable large systematic error was found. This error came from the exciting current of the switching relay used for the peak matching. In order to obtain the final values of the measured doublet mass differences, the estimations of the magnitudes of expected systematic errors were done. Moreover, using the closure error of the triplet derived from the mass differences of the above mentioned doublets, the correction factor for the measured values was calculated, and the mass differences corrected by this factor are adopted as the most reliable values for $\left(\mathrm{N}_{2}-\mathrm{CO}\right)$, $\left(\mathrm{C}_{2} \mathrm{H}_{4}-\mathrm{N}_{2}\right)$ and $\left(\mathrm{C}_{2} \mathrm{H}_{4}-\mathrm{CO}\right)$ doublets. Finally, the doublet mass difference of $\left(\mathrm{C}_{2} \mathrm{H}_{4}-\mathrm{C}_{2} \mathrm{D}_{2}\right)$ was measured.

Relating to the photographic method, the investigations on mass calibration have been carried out by $\mathrm{S}$. Matsumoto in our laboratory and the reports are found in other place. ${ }^{7,8,9)}$

\section{Instrumentation}

The characteristics of the newly reconstructed double focusing mass spectroscope were previously reported,") in detail. So here, only the schematic general view of the machine is shown in Fig. 1, and the improved and modified points for the instrumentation and the performance will be described in the following sections.

\subsection{Ion source assembly}

The ion source and the accelerating lens system previously used have been replaced with the new ones, in which adjustments are possible to increase an extracting efficiency of ions produced in the ionizing chamber. The location and direction of the ionizing chamber can be adjusted finely againt the ion accelerating lens system. And, one more cylindrical electrode is added between the first grounded electrode of the lens system 


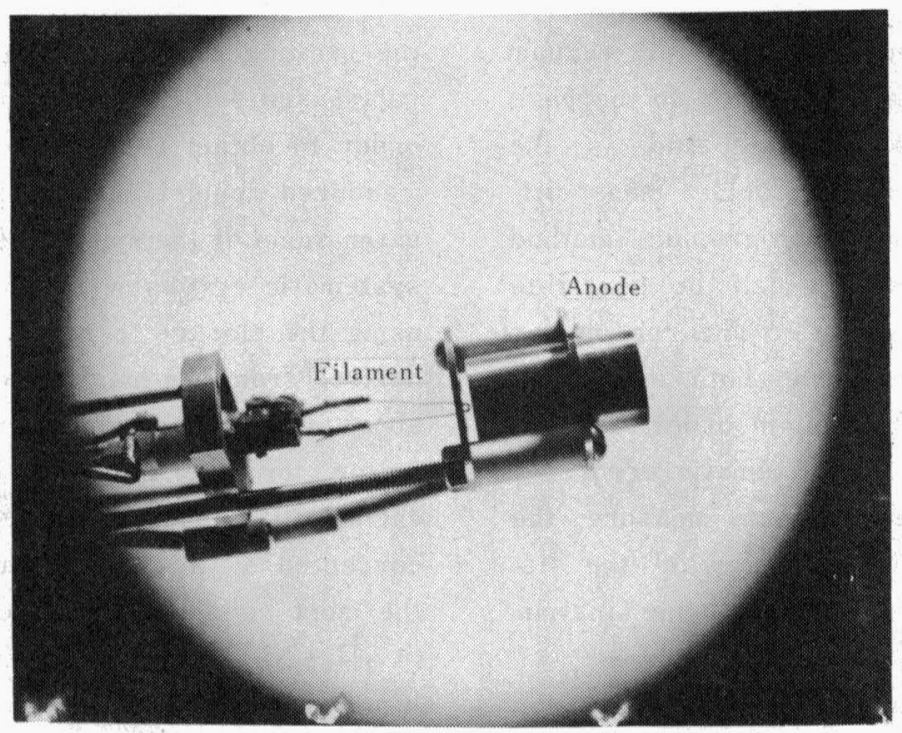

Fig. 2. View in the arc chamber

and the ionizing chamber. An appropri ate potential is applied to the electrode so as to extract ions from the chamber efficiently as much as possible, and the good alignment of the chamber against the lens system can be done by the adjustment devisings attached to the ion source assembly.

Though the type of discharge for ion production is a kind of low voltage arc, as in the previous case, some technical improvements have been performed at the part of filament's ends. In the previous case, the leg of filament was screwed to a small stainless steel block, and the filament was frequently gone at the leg portion of a few $\mathrm{mm}$ apart from the steel block. Then, it had been very difficult to maintain the discharge condition to be stable for rather long time. In the present case, the filament is attached to the steel block through the stainless steel wire of $1 \mathrm{~mm} \phi$ welded to the end of the filament, and metal parts near the filament are removed as much as possible. As the result of such improvements for filament, the life of the filament is considerably elongated and the continuous stable opration of discharge can be realized. The contsruction of the filament part in the arc chamber is shown in Fig. 2.

In order to get the more stable discharge, an emission stabilizer with lead batteries as a primary source was adopted. The ion current of about 30 $\mu A$ is extracted from the arc chamber, and this total ion current can be held to be roughly constant through the stabilizer by properly setting of the emission current and of the source magnet current. In this case, the pressure of sample gases in the chamber does not affect the operating condition of discharge within an allowable range of the total pressure. In Fig. 3, the circuit diagram of the ion source supply, including the emission stabilizer, is shown. For controlling the sample pressure in the ion source, three adjustable gas 
Mass Differences; $\left(\mathrm{C}_{2} \mathrm{H}_{4}-\mathrm{CO}\right),\left(\mathrm{C}_{2} \mathrm{H}_{4}-\mathrm{N}_{2}\right),\left(\mathrm{N}_{2}-\mathrm{CO}\right)$ and $\left(\mathrm{C}_{2} \mathrm{H}_{4}-\mathrm{C}_{2} \mathrm{D}_{2}\right)$

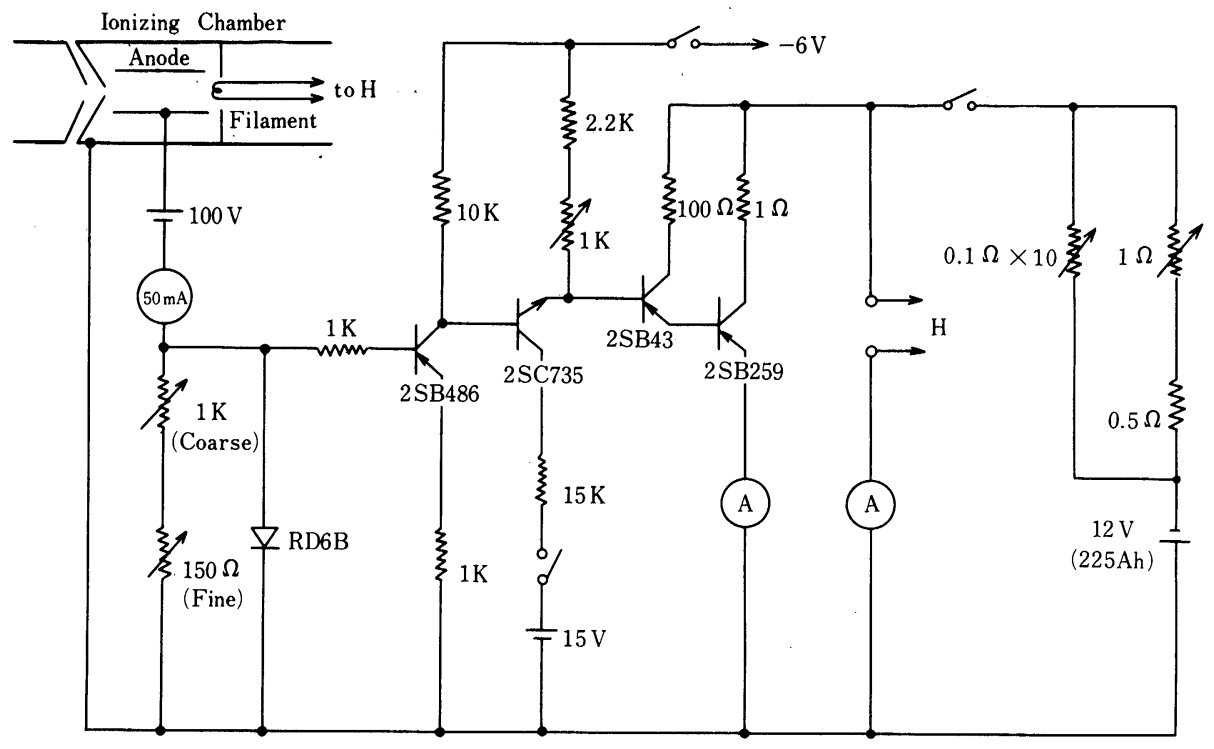

Fig. 3. Circuit for the ion source supply

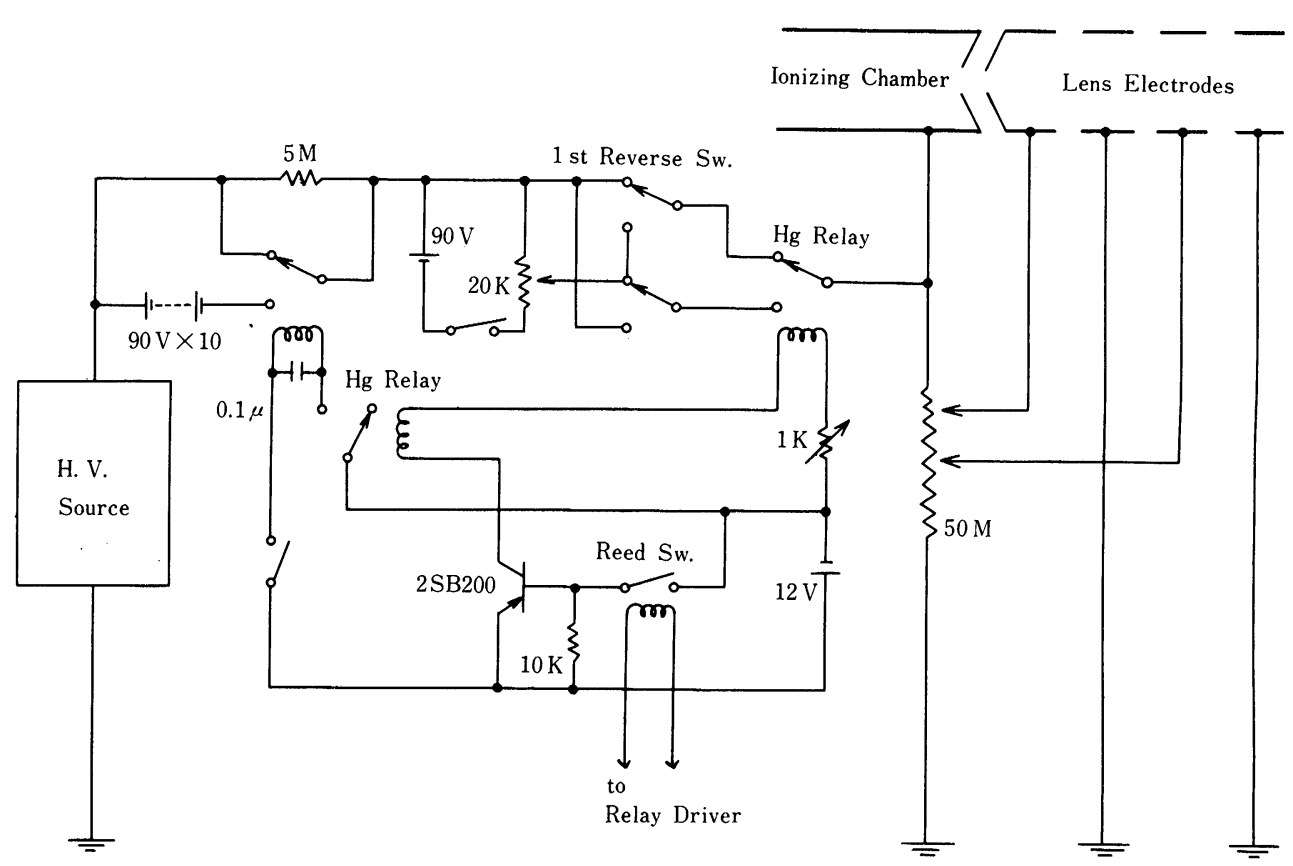

Fig. 4. High voltage switching circuit 
leaks are used, and each leak valve is followed by a sample gas reservoir. These gas leaks control finely the pressures of sample gases independently within the allowed range of the total pressure indicated by a thermocouple gauge.

By inserting the emission stabilizer to the ion source circuit, besides the improvement at the filament construction, above mentioned, the good reproducibility for the operating condition of ion source is obtained, and the well focused and stable ion beam can be easily extracted from the arc chamber.

A home-made relay, used for switching the difference of about 1000 volts, was added in the H. V. switching circuit. This H. V. switching is used for the check of mass dispersion coefficient by using one hydrogen mass difference doublet. Fig. 4 shows the present H. V. switching circuit diagram.

\subsection{Ion detector system}

In order to finely find out the good focusing position and to obtain the well shaped mass peak, a new collector slit system is installed at the double focusing point. The slit width, its inclination and its lateral location can be adjusted from outside of the vacuum chamber.

A secondary electron multiplier of 16 -stages is used in the present case, and the gain is estimated to be about $10^{5}$. In previous case, a 10-stages multiplier and $10^{10} \Omega$ input resistor for the followed d. c. amplifier were used. But, in the present case, on account of the increase of the multiplier gain, $10^{8} \Omega$ input resistor is sufficient for getting the appropriate amplification of overall ion current measuring system. As the result, the d.c. amplifier can response for faster scanning of ion beam than in the previous case.

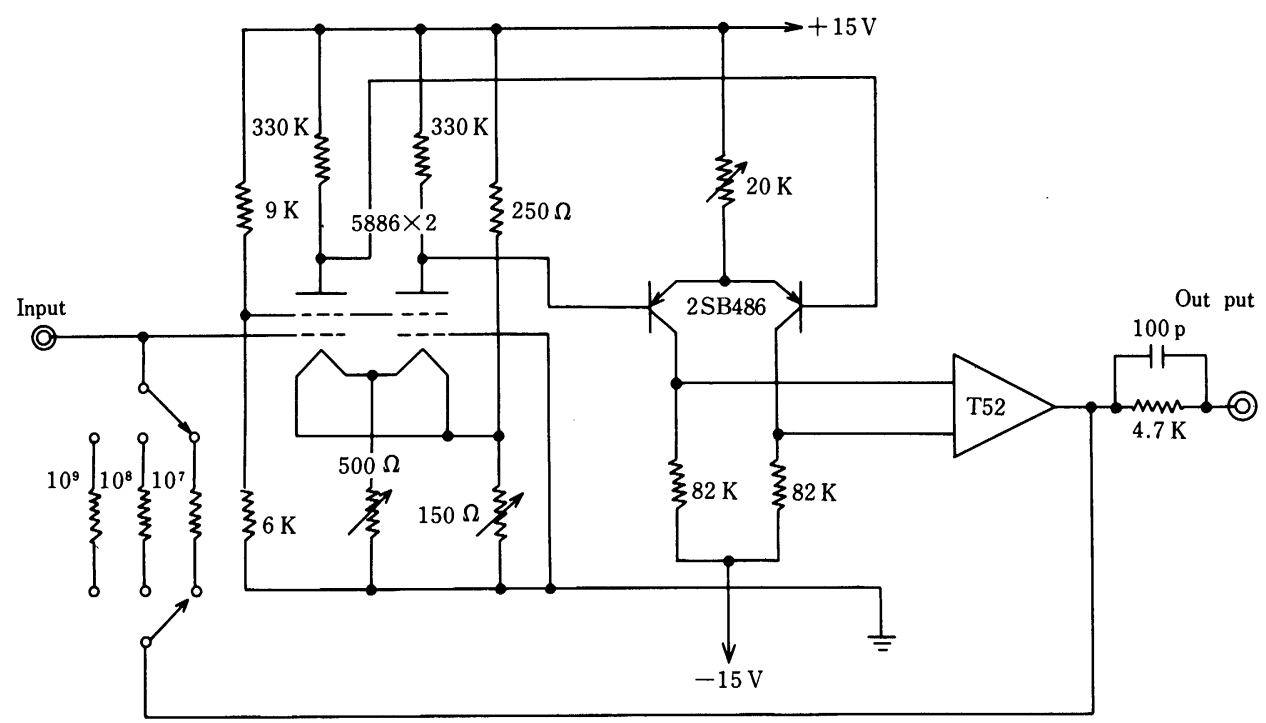

Fig. 5. D. C. amplifier 
For the d.c. amplifier, some modifications are preformed, and the circuit diagram is shown in Fig. 5. With the modifications, a high frequency noise was considerable lowered in comparing with the previously used amplifier.

\subsection{Peak matching switching circuitry}

The switching circuitry and the time sequence for peak matching have been quitely alternated. The scanning rate of ion beam, which was $10 \mathrm{c} / \mathrm{sec}$. or so formerly, is fastened to $30 \mathrm{c} / \mathrm{sec}$. or higher. Even for such faster scanning, any distortion of mass peak shape is not recognized in the present case. On the other hand, if the switching frequency of the electric field is as high as that of the ion beam scanning above mentioned, the transient effect, associated with the relay switching, may not be able to neglect. Therefore, the switching frequency of all of relays is lowerd to 2 $5 \mathrm{c} / \mathrm{sec}$., and the synchroscope input is grounded by the amount of about 40 msec., i.e. the interval that the transient effect can not be negligible, after the switching of relays. The block diagram and the phase relation of peak matching switching circuitry are shown in Fig. 6 and Fig. 7. The period of ion beam scanning and its saw tooth type waveform are matched to that of the horizontal sweep of synchroscope, which is internally synchronized to the a. c. line. The voltage to current convertor for exciting the scanning coils of Helmholtz type was also modified so as to scan the ion beam more widely and to adjust finely the timing of zero field. In Fig. 8, the modified circuit diagram is shown.

\subsection{Peak matching circuit}

The peak matching circuit, which is shown in Fig. 9, has been newly constructed. All of the fixed resistors used in this circuit are of Julie Research Laboratories type $\mathrm{CH}-44$ with a temperature coefficient of $5 \mathrm{ppm} /{ }^{\circ} \mathrm{C}$.

The main bleeder $R$, as well as the slave bleeder $R^{\prime}$, is constructed of fifty $100 K \Omega$-resistors to form a total resistance of $5 \mathrm{Meg} \Omega$. These resistors were selected from a larger group and are matched with one another to better than 100 ppm. $\Delta \mathrm{R}$ consists of five

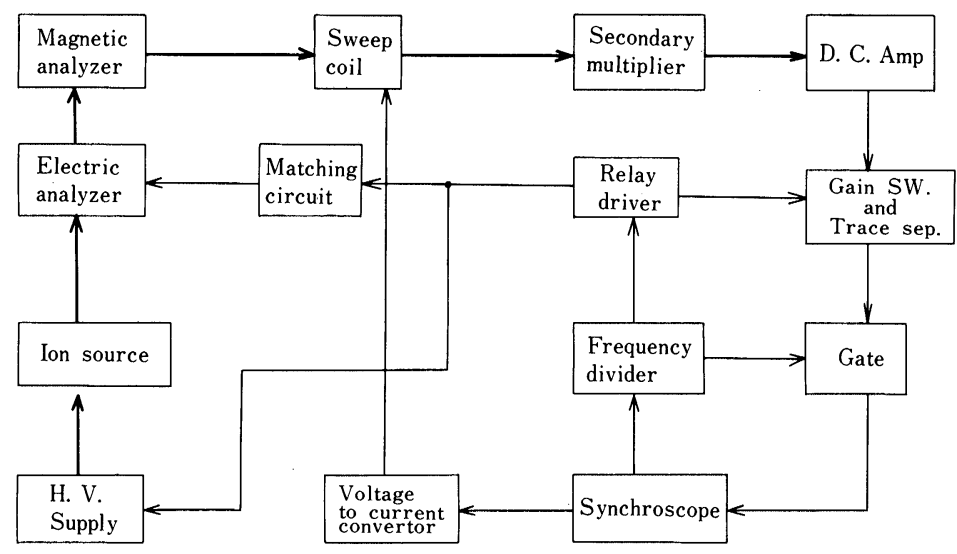

Fig. 6. Block diagram of the peak matching switching circuitry. 


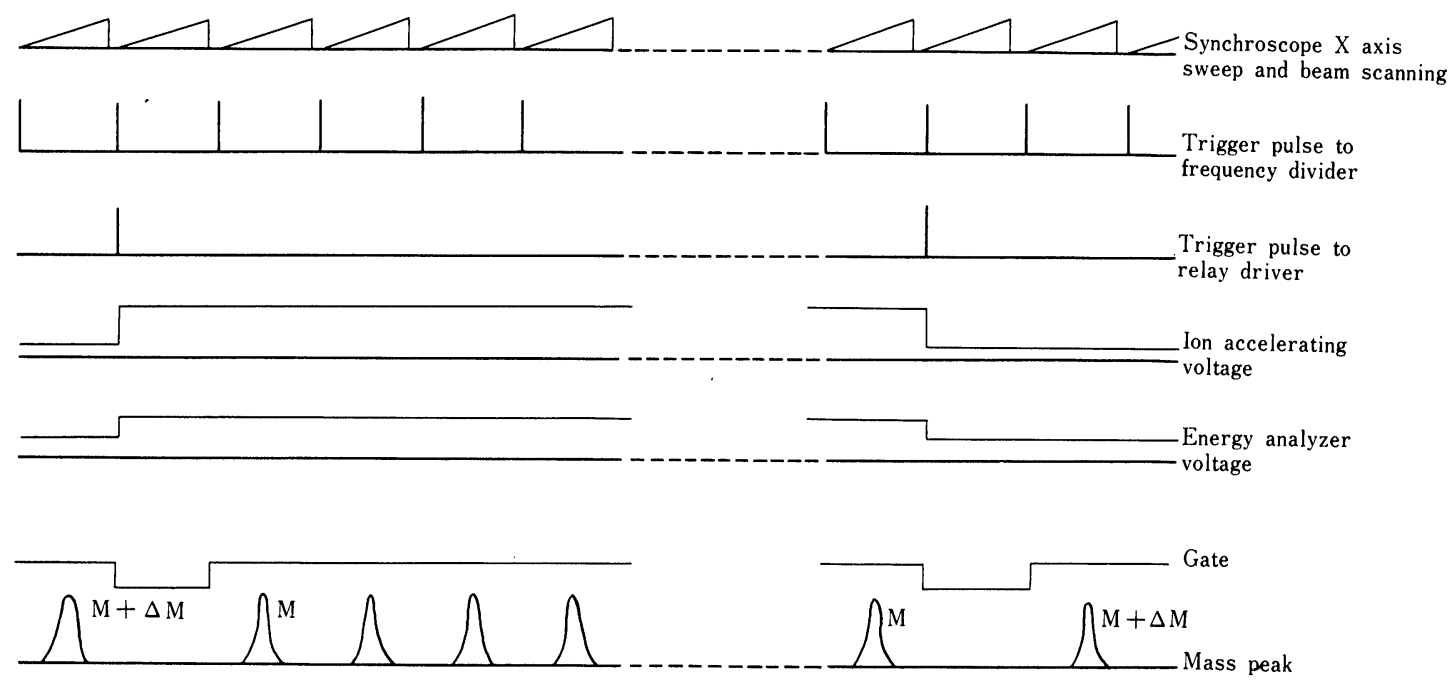

Fig. 7. Phase relation of the peak matching switching circuitry

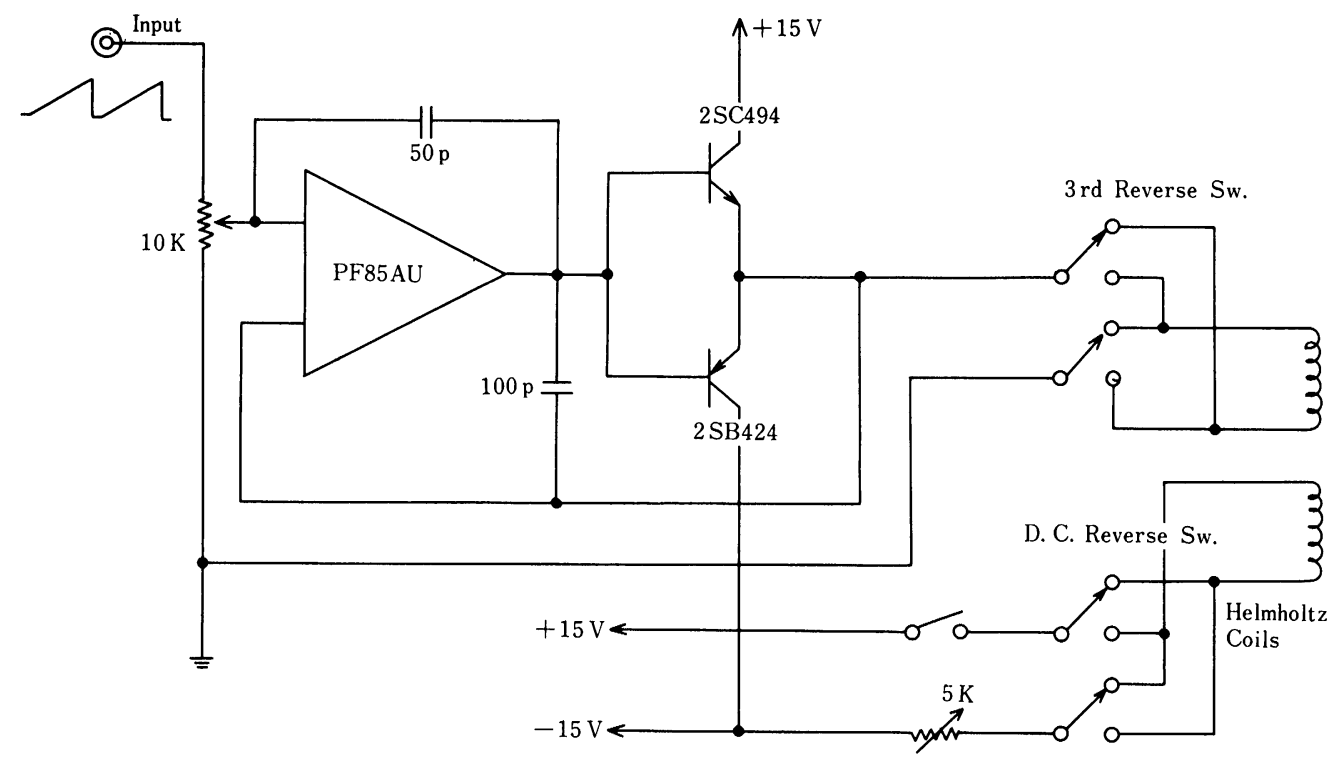

Fig. 8. Voltage to current convertor for exciting the scanning coil 
Mass Differences; $\left(\mathrm{C}_{2} \mathrm{H}_{4}-\mathrm{CO}\right),\left(\mathrm{C}_{2} \mathrm{H}_{4}-\mathrm{N}_{2}\right),\left(\mathrm{N}_{2}-\mathrm{CO}\right)$ and $\left(\mathrm{C}_{2} \mathrm{H}_{4}-\mathrm{C}_{2} \mathrm{D}_{2}\right)$

decades of $20 K \Omega, 2 K \Omega, 200 \Omega, 20 \Omega$ and $2 \Omega$ per step and of a $20 \Omega-20$ turn helical potentiometer. All of resistors are set in an acrylic box, in which each of $\Delta R, R$ and $R^{\prime}$ is grouped seperately along the side wall of the box. This acrylic box is mounted in a temperature controlled box, which walls are surrounded by polystrol foam, and in which closed air continuously circulates so as to obtain the uniform temperature distribution in the box. On the way of the air circulating pass, there is a tunnel which runs out of and from one side to another of the temperature controlled box and in which a fan, a main heater and an auxiliary one are installed. The temperature in the box is estimated to be uniformly controlled in $\pm 0.1^{\circ} \mathrm{C}$ at adout $30^{\circ} \mathrm{C}$. In Fig. 10, is shown the proportional temperature regulating circuit diagram. Each resistor of the R, as well as the $\Delta R$, is connected with each other in series in the acrylic box, and each lead between any pair is brought out by the thick copper wire and connected to the copper terminal on the acrylic plate of the outside wall of the temperature controlled box, so as to make up externally the parallel combination with all of $100 \mathrm{~K} \Omega$ resistors, as well as of resistors of each decade. The setting of $\Delta R$ is performed with appropriate connection of resistors of each decade at the external terminals and with continuous variation of $20 \Omega$ helical potentiometer.

\section{Experimental procedures and the results}

\subsection{Calibration of the resistance ratio}

One can show that the mass difference between two members of a mass doublet is related to the electrostatic deflection voltage according to the equation:

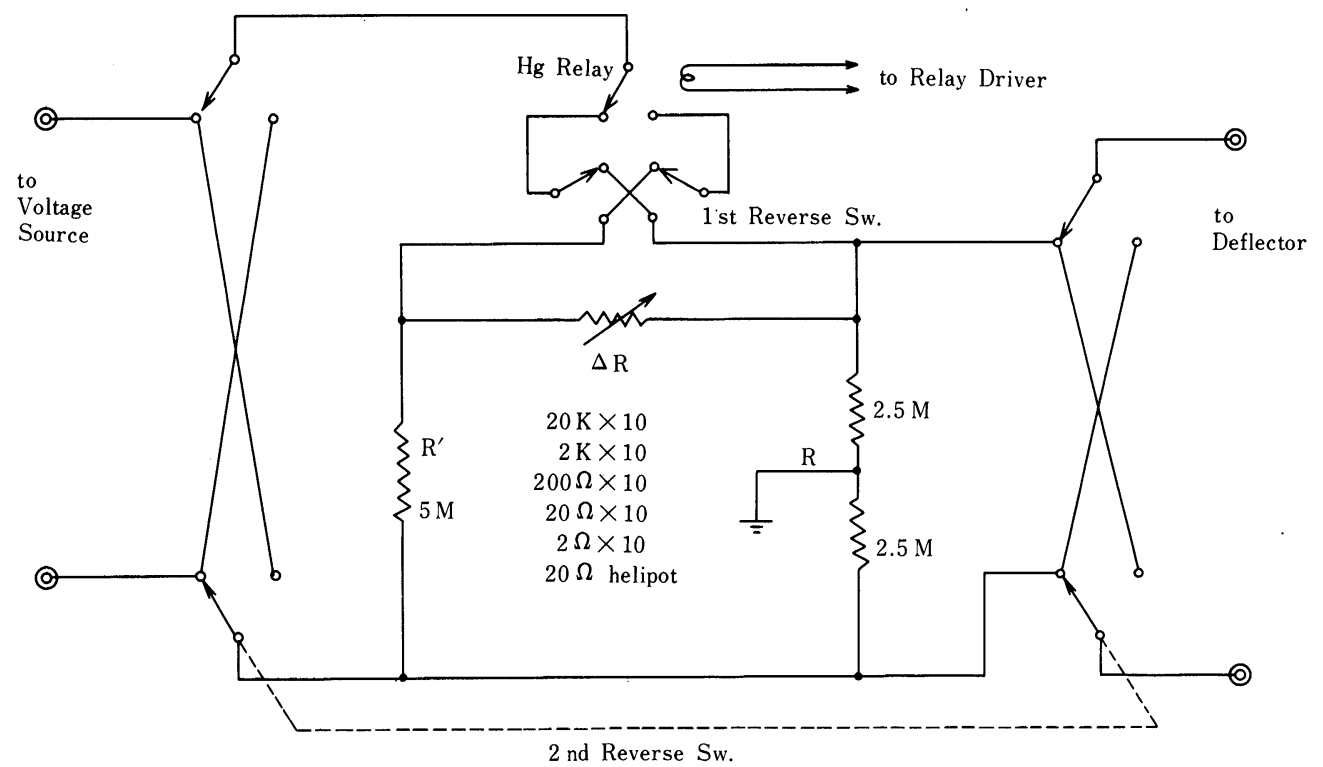

Fig. 9. Peak matching circuit for the mass difference measurement. 


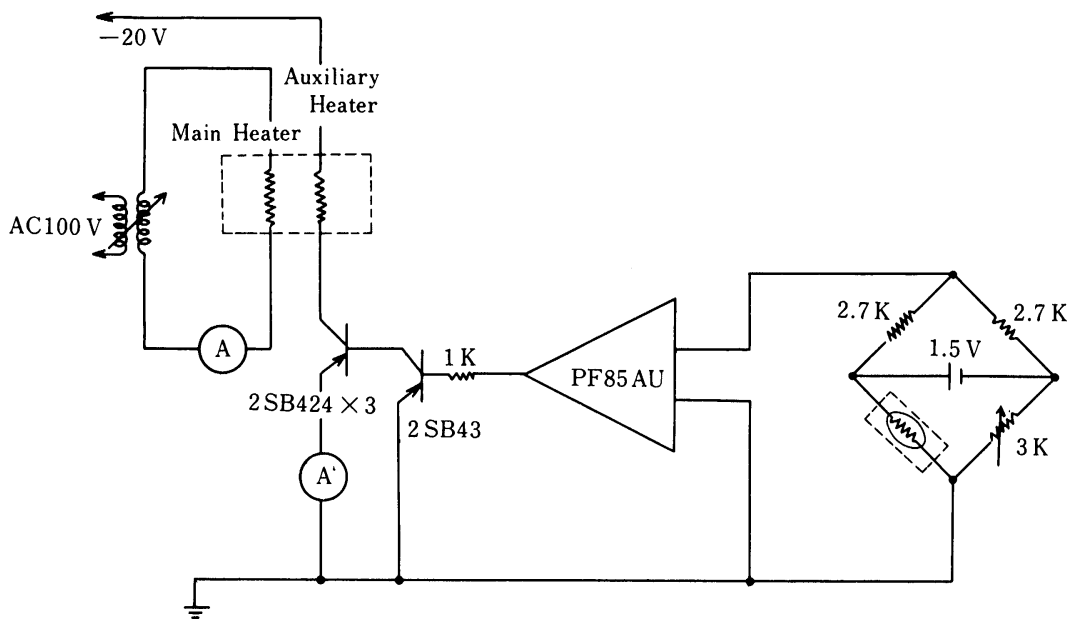

Fig. 10. Temperature regulating circuit for the peak matching circuit.

$$
\frac{\Delta M}{M}=\frac{\Delta V}{V}
$$

where $\Delta M$ is the doublet mass difference, $M$ is the ionic mass of lighte $r$ member collected with the deflection voltage $V$, and $\Delta V$ is the change in deflection voltage necessary to cause the heavier member of the doublet, $M+\Delta M$, to also be focused at the collector slit. In actual application, this deflection voltage is supplied through the so-called peak matching circuit shown in Fig. 9 to the electrostatic analyzer. ${ }^{10)}$ The voltage ratio is directly related to the resistance ratio, i. $e$.

$$
\frac{\Delta M}{M}=\frac{\Delta R}{R} \text {, }
$$

where $\Delta R$ is the value of the variable resistance required for the peak matching and $R$ is the value of the total fixed resistance as shown in the figure. Then, the precision of the mass doublet measurement depends to a large extent on the precision with which one is, able to reliably determine the resistance ratio. In this section, the resistance calibration procedure used in the present work is described.

In general, the relation between the series combination and the parallel one, which are made up from $N$ resistors, is followed to

$$
R_{\text {series }}=N^{2} \cdot R_{\text {para }}
$$

in the first approximation in terms of deviations among the resistances. Each $100 \mathrm{~K} \Omega$-resistor used in the main bleeder $\mathrm{R}$ is with each other matched within one part in $10^{4}$. Accordingly, for the main bleeder consisting of fifty $100 \mathrm{~K} \Omega$ resistors, the following relation holds in an accuracy of less than $10^{-8}$ : 
Mass Differences; $\left(\mathrm{C}_{2} \mathrm{H}_{4}-\mathrm{CO}\right),\left(\mathrm{C}_{2} \mathrm{H}_{4}-\mathrm{N}_{2}\right),\left(\mathrm{N}_{2}-\mathrm{CO}\right)$ and $\left(\mathrm{C}_{2} \mathrm{H}_{4}-\mathrm{C}_{2} \mathrm{D}_{2}\right)$

$$
R \equiv R_{\text {series }}=(50)^{2} \cdot R_{\text {para }}
$$

One can measure $R_{\text {para }}$ which is a resistance value in the parallel combination of fifty $100 \mathrm{~K} \Omega$-resistors and is equal to $2 K \Omega$, in order to know accurately $R$. The quantity to be known is not the absolute value of the resistance but the ratio value, and the standard resistance can be arbitrarily chosen. In the present case, $R_{\text {para }}$ is assumed to be equal to 2 $K \Omega$.

Each $\Delta R$ and $R_{\text {para }}$ were measured using a commercial Wheatstone Bridge . The Wheatstone Bridge (YOKOGAWA $B D-1 B)$ used in the present work is of a sensitivity of $10^{-5}$, but of an accuracy of $10^{-4}$, and the resistors in the Bridge are of a nominal temperature coefficient of $10^{-5} /{ }^{\circ} \mathrm{C}$.

In order to measure the resistance value within an accuracy of $10^{-5}$ using this Bridge, resistors of $1 K \Omega$ - and 100 $\Omega$-decades of the measuring region of the Bridge were calibrated by means of another Wheatstone Bridge of the same type. Assuming that the averaged value of ten $1 \mathrm{~K} \Omega$-decade resistors is $1 \mathrm{~K} \Omega$, each value of $1 K \Omega$ - and $100 \Omega$ decade resistors was determined in an accuracy of $10^{-5}$. In this case, the parallel combination of ten $1 K \Omega$-decade resitors was measured at the same range as that used in the $100 \Omega$-decade resistor measurement, referring to the relation of Eq. 3. As the result, each determined value of $1 K \Omega$-decade resistor may be unknown in the order of magnitude of 1 $m \Omega$, but not that of $100 \Omega$-decade resistor. So, it is reasonable to assume that each $1 K \Omega$-decade resistor has a maximum uncertainty of $10 \mathrm{~m} \Omega$. In measuring any resistor using the calibrated
W. B., the resultant uncertainty associated with the measured value is estimated in terms of the product of $10 \mathrm{~m} \Omega$ which is the uncertainty attached to each $1 K \Omega$-decade resistor and the square root of the number of $1 K \Omega$-decade resistor used. The uncertainty thus calculated is taken account for in the final analysis of measured mass differences.

The W.B. used for $\Delta R$ and $R_{\text {para }}$ measurement was outside the temperature controlled box, and then the temperature surrounding the W. B. is nearly equal to the room temperature which is roughly controlled. Each $\Delta R$ and $R_{\text {para }}$ are of a nominal temperature coefficient of $5 \mathrm{ppm}$ $/{ }^{\circ} \mathrm{C}$, and the temperature of the box is controlled within $\pm 0.1^{\circ} \mathrm{C}$.

So the temperature variation of $\Delta R$ as well as $R_{\text {para }}$ may be negligible small. On the other hand, however, the W. B. used has a temperature coefficient of $10 \mathrm{ppm} /{ }^{\circ} \mathrm{C}$ and the room temperature is probably fluctuated in the range of \pm 2 ${ }^{\circ} C$. Consequently, the values given by the calibrated W. B. are subject to the temperature variation of the W. B. itself. As the result, the variation of the measured resistance value higher than $1 \mathrm{~K} \Omega$ was estimated to be one part in $10^{5}$ and that of the ratio againt $R_{\text {para }}$ to be some parts in $10^{6}$.

Of course, such resistance calibration method may not be the best one. It is desirable that the W. B. has to be installed in the temperature controlled box, together with the resistors to be measured. In near future, some im. provements for the resistance calibration procedure will be carried out. In this case, the same resistors as that used for the present matching circuit will be used for the resistors of the planning bridge and the bridge will be set up in 
Table 1. Various sources of systematic errors

\begin{tabular}{l|lll}
\hline \hline \multirow{*}{*}{$\begin{array}{l}\text { peak matching } \\
\text { circuit }\end{array}$} & electro-motive force in $\Delta \mathrm{R}$ & $\beta$ & check \\
& electro-motive force in $\mathrm{R}$ & $\alpha$ & negligible \\
& leakage resistance & $\alpha$ & negligible \\
& transient effect & $\alpha$ & negligible \\
& relay contact potential & $\alpha$ & negligible \\
& relay contact resistance & $\beta$ & check \\
& surface contact potential & $\beta$ & check \\
\hline \multirow{2}{*}{ instrument } & asymmetry of peak shape & $\alpha$ & estimation \\
& stray magnetic field from relay coil & $\beta$ & check \\
\hline
\end{tabular}

the temperature controlled box.

\subsection{Investigation of systematic errors}

In the previous work, it was found that the very weak magnetic field affected seriously the measurement of doublet mass difference and that the field strayed out from the exciting coil of the relay used for peak matching. This systematic error was almost overcome by keeping away the pannel installing the peak matching circuit from the ion beam trajectory. In the present work, the investigations were mainly

concentrated to search other systematic errors. Some causes of systematic errors could be expected and these amounts could be evaluated. However, some unexpected systematic errors should be still remained. In order to take account of these systematic errors, the following transformations are as. sumed:

$$
\frac{\Delta M}{M}=(1+\alpha) \cdot \frac{\Delta R}{R}
$$

and

$$
\frac{\Delta M}{M}=\frac{\Delta R}{R}+\beta
$$

As for the factors which may cause systematic errors, two different kinds of ones could be considered. One of them is $\alpha$ appeared in Eq. 5, and the factor has influence on the mass difference $\Delta M$ in proportion to the mass difference itself. On the other hand, the factor $\beta$ appeared in Eq. 6 . has influence on $\Delta M$, independent of the magnitude of $\Delta M$. Taking account of an expected measuring accuracy in the present investigation, if $\alpha$ and $\beta$ is less than $10^{-5}$ and $10^{-8}$ respectively, the systematic errors indebted to these factors may be almost negligible.

In Table 1. various sources of systematic errors which may exist are listed up and are separated to the causes coming from the peak matching circuit and the instrumental causes. The quantities denoted by "check" are ones checked throughout the investigation with the measurement of mass difference. In this case, some reversing techniques, by which the reversed effects of the quantities to be checked are produced, have been applied to the investigation. The quantity denoted by "estimation" can not be found with any effective reversing operation. So this effect is estimated by measuring the reference doublet whose mass difference is accurately known. The quantities denoted by "negligible" were neglected by devising, or by measuring the quantities themself, it was 
Mass Differences; $\left(\mathrm{C}_{2} \mathrm{H}_{4}-\mathrm{CO}\right),\left(\mathrm{C}_{2} \mathrm{H}_{4}-\mathrm{N}_{2}\right),\left(\mathrm{N}_{2}-\mathrm{CO}\right)$ and $\left(\mathrm{C}_{2} \mathrm{H}_{4}-\mathrm{C}_{2} \mathrm{D}_{2}\right)$

found that their effects were negligible. Despite of the above investigations, some unknown and unavoidable parts causing systematic errors may be remained in $\alpha$ as well as $\beta$. The resultant of $\alpha$ is well estimated by measuring the reference doublet as just mentioned. And, in the present case, the closure error of three possible doublets of a triplet may be valuable for the evaluation of the resultant amount of $\beta$.

At first, the errors included in the factor $\alpha$ in Eq. 5 were estimated.

\section{bleeder misnatch}

In Fig. 9, the resistance values of the main bleeder $R$ and the slave one $R^{\prime}$ are nominally equal with each other. So, the peak matching circuit operates as a constant current circuit when the circuit is switched. Actually, the match of both bleeders is estimated to be within 100 ppm, and this matching accuracy is verified with the Wheatstone Bridge. And, an internal resistance of the power source suppling the voltage to the circuit is estimated to be much smaller than that of bleeder. Thus, the error coming from such mismatching may be completely negligible.

\section{leakage resistance}

A leakage resistance to the ground from the whole system, including the divider, the power source, the cylindrical electrodes of the energy selector and the cables, may cause a fractional effect to the resistance ratio because of the comparatively large resistance of the bleeder. The leakage current was measured and resulted in the leakage resistance of excess of $10^{13} \Omega$. The effect of this leakage would be a few parts in $10^{7}$ of the measured mass difference and may also be negligible.

Similarly, a leakage between the relay contacts, i.e. across $\Delta R$, may caused some effect on the measured ratio. Since each $\Delta R$ measured in the present work is less than $10^{4} \Omega$, the effect of this leakage, when larger than $10^{9} \Omega$, would be negligible for the ratio. In the present work, also, each $\Delta R$ was measured by the Wheatstone Bridge including this leakage resistance.
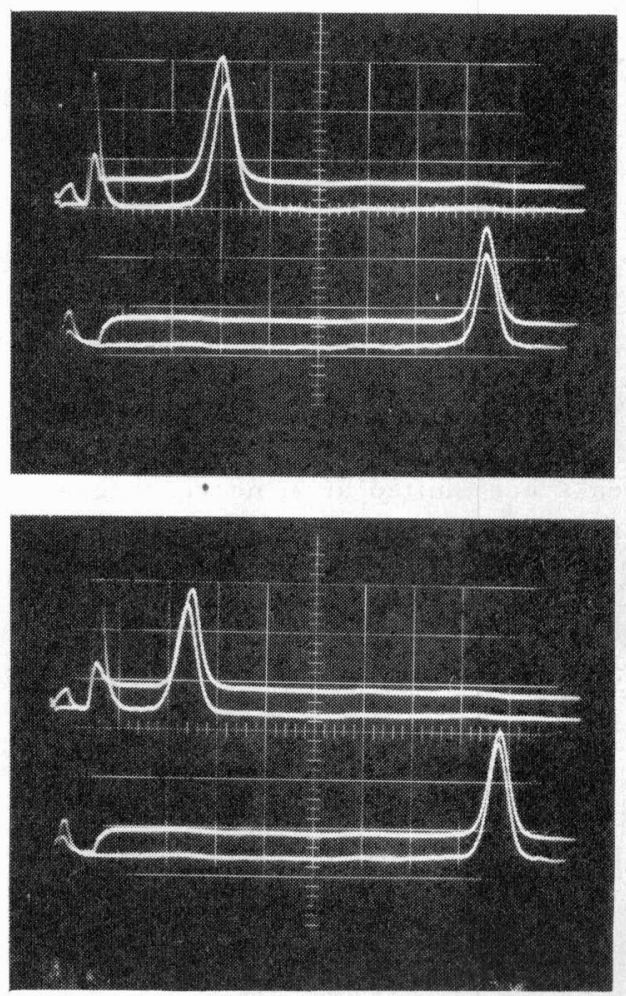

Fig. 11. Mismatching of peaks by the transient effect. $\Delta R$ is fixed to a certain amount in each mismatching or matching. The upper photograph is the case performed with the "normal" operation of the second reversing switch and the lower one is with the "reverse" operation.

\section{transient effect}

As shown in Fig. 9, the whole system relating to the peak matching circuit is hung on only one grounded 
point. A time constant in charging the capacitance between the system and the ground coupled with the bleeder resistance gives some important transient effect, when the circuit is switched. It is possible to observe the error produced by such transient effect on the synchroscope, and slight different settings in $\Delta R$ will be acquired at different positions of matched peaks on the synchroscope trace. This was done and such effect can be seen in Fig. 11, at the switching frequency of $30 \mathrm{c} / \mathrm{sec}$. and using the $\left(\mathrm{N}_{2}-\mathrm{CO}\right)$ doublet. The upper photograph is the case performed with the "normal" operation of the second reversing switch which is mentioned later, and the lower one is with the "reverse" operation. The lower trace of each photograph presents the matched peaks at a nearly end of the switching period in a certain setting of $\Delta R$. After then, two mass peaks are shifted at a nearly beginning of the period in the some setting of $\Delta R$. As shown in the upper trace of each photograph, this results in the mismatched peaks, and this mismatching effect is inversed with the second reversing operation. The time constant to the ground of the whole system was estimated to be about 3 msec., by observing the square wave form applied to the analyzer. On the other hand, the time constant between the electrodes of the electric analyzer can be estimated to be negligible small, because, in this case, the effective resistance is replaced by the internal resistance of power source which is much smaller than that of the bleeder.

The time interval necessary for each electrode of the analyzer to reach the final value within one part in $10^{6}$ to the ground is calculated to be about 35 msec. after switching of the matching circuit. The error due to such transient effect can be well eliminated, if the devising is made such that the mass peaks are not traced until the effect becomes to be negligible. The modifications of the peak matching switching circuitry were performed, as is already mentioned. In the switching interval of the matching circuit which is ordinarily $200 \sim 400$ msec., the vertical input of synchroscope is connected to the ground potential with a reed switch operated by the gate pulse, during about $40 \mathrm{msec}$. after switching of the relay. The delay time of relay, i.e. from a triggered instant to that a voltage change occurs, is estimated to be about 5 msec. and also taken account.

electro-motive force in the main bleeder $R$.

Because of that the magnitude of the electro-motive force in $\mathrm{R}$ may be 20 $m V$ in the maximum to give the error caused from the e.m.f. in one part in $10^{5}$ against the voltage of about $2000 \mathrm{~V}$ supplied to the energy analyzer, it is easily supposed that this e.m. $f$. give a negligible effect. However, the checking for this effect was done by reversing the current through the bleeder R. In such a case, the deviations due to this effect are inversed.

\section{surface contact potential}

With regard to the effect of a surface contact potential which may exist on either of the energy analyzer electrodes, it is quite impossible not only to estimate such a potential itself but also to eliminate such an effect with reversing technique. The measurement of one hydrogen mass difference, which is known in satisfactry accuracy, can be used for finding 
Mass Differences; $\left(\mathrm{C}_{2} \mathrm{H}_{4}-\mathrm{CO}\right),\left(\mathrm{C}_{2} \mathrm{H}_{4}-\mathrm{N}_{2}\right),\left(\mathrm{N}_{2}-\mathrm{CO}\right)$ and $\left(\mathrm{C}_{2} \mathrm{H}_{4}-\mathrm{C}_{2} \mathrm{D}_{2}\right)$

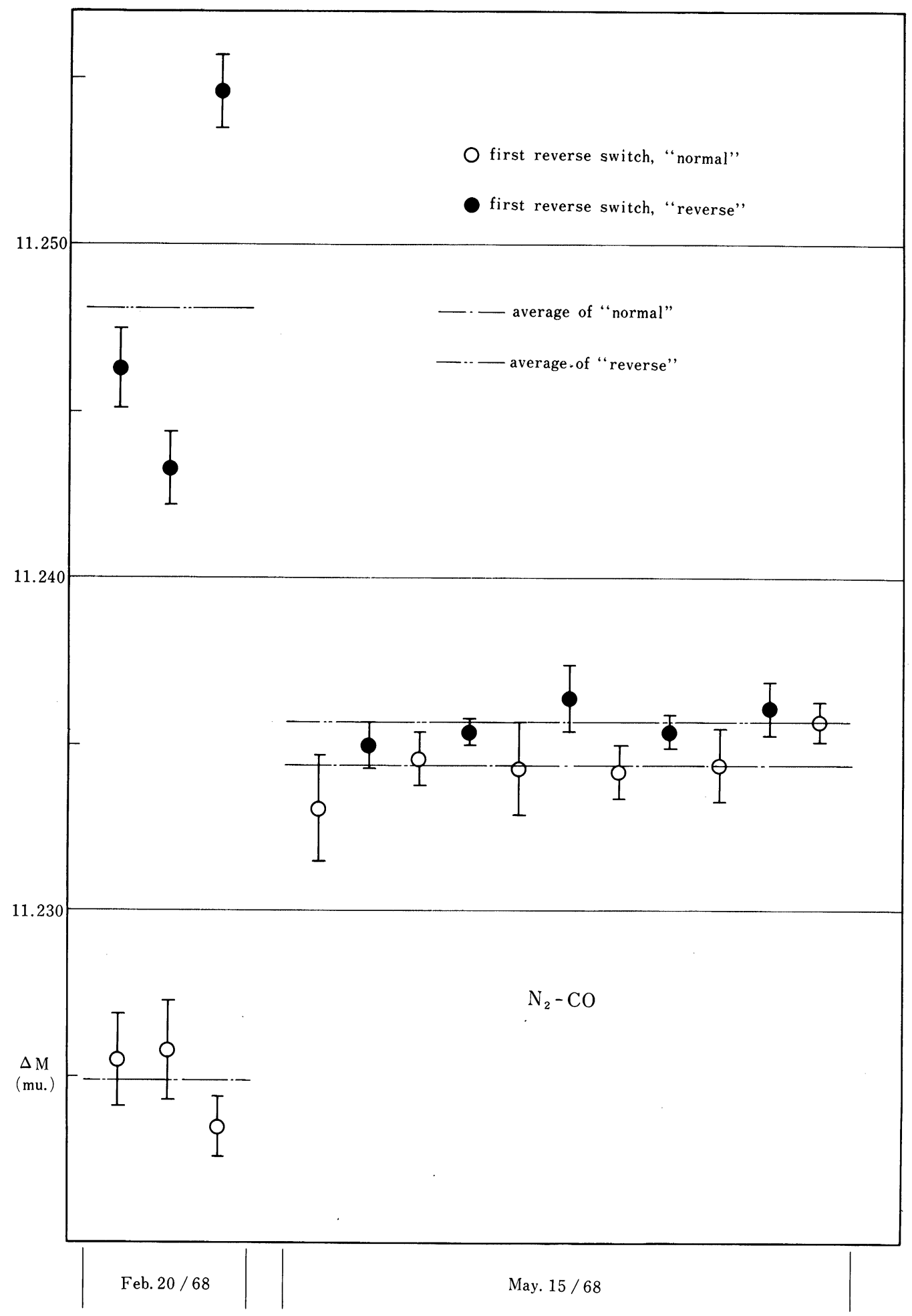

Fig. 12. Mass differences measured with the first reversing operation 
such an effect. When the hydrogen mass measured is largely deviated from the known value, the surfaces of the energy analyzer electrodes may be contaminated with insulated oil film. In such a case, the electrodes have to be cleaned up.

In order to estimate the amount of the correction factor $\alpha$ coming from the cause above mentioned, the mass difference measurements of $(\mathrm{COH}-\mathrm{CO})$ and $\left(\mathrm{N}_{2} \mathrm{H}-\mathrm{N}_{2}\right)$ doublets were carried out. The $\alpha$ thus determined includes the correction for unexpected errors besides that for charging up effect on the surface of the electrode just above mentioned. The measurements of above mentioned doublets were averaged to be the measured value of hydrogen mass 1.007.861士 $5 \mathrm{u}$. This value is compared with the accepted value $1.007825 \mathrm{u},{ }^{2)}$ and results in $1+\alpha=0.999964$. As the result, the amount of $\alpha$ is estimated to be $-3.6 \times$ $10^{-5}$, and this value of $\alpha$ determined is comparable with the present accuracy of the mass difference measurement. However, the $\alpha$-correction is that for systematic errors, not for statistical ones, so the measured mass differences have to be corrected with this $\alpha$ for getting the final value of doublet mass differences. In this case, although the error for $\alpha$ determined is about five parts in $10^{6}$, this amount may be neglected for the final results.

Next, for evaluating another correction factor $\beta$ appeared in Eq. 6, the following considerations and procedures were performed. In this case, some suitable reversing operations were introduced such that the effects which may be positive in one arrangement are negative in another one. The deviation between the positive effect and the negative one may be estimated to be twice of the absolute effect in either arrangement, and both effects may be averaged to be zero.

\section{first reversing operation}

By operating the first reverse switch shown in Fig. 9, one can observe a high or a low member of the mass doublet when the relay coil is exciting, and denote the former by "normal" and the latter by "reverse". The effects which may be caused by a certain contact potential or contact resistance existing at the relay contacting portion will be reversed with this reversing operation. In the previous work, this operation was adopted with the purpose of the check of such effects. However, in the measurement of $\left(\mathrm{N}_{2}-\mathrm{CO}\right)$ doublet mass difference, a very large systematic discrepancy between the valuse obtained with the first reversing operation was found. The discrepancy is shown in the left side of Fig. 12. In the figure shown in this section, each plot and the arrow attached to the plot indicate the average of ten or so matchings of peaks and the statistical error of the average, respectively. The alternate measurements of "normal" and "reverse" were treated. This large discrepancy, $\delta(\Delta M)$, is estimated to be about $20 \mu u$, and the amount corresponds to about eight parts in $10^{7}$ in terms of $\beta=\delta(\Delta M) / M$. When such an effect is assumed to come from a contact potential or a contact resistance, the amount is estimated to be a potential of about $0.8 \mathrm{mV}$ against $2000 \mathrm{~V}$ across the deflecting plates of the energy selector, or a resistance $0.6 \Omega$ against $3 \mathrm{Meg} \Omega$ of the bleeder resistance of the previous matching circuit. These amounts thus estimated were too large to be expected. 
Mass Differences; $\left(\mathrm{C}_{2} \mathrm{H}_{4}-\mathrm{CO}\right),\left(\mathrm{C}_{2} \mathrm{H}_{4}-\mathrm{N}_{2}\right),\left(\mathrm{N}_{2}-\mathrm{CO}\right)$ and $\left(\mathrm{C}_{2} \mathrm{H}_{4}-\mathrm{C}_{2} \mathrm{D}_{2}\right)$

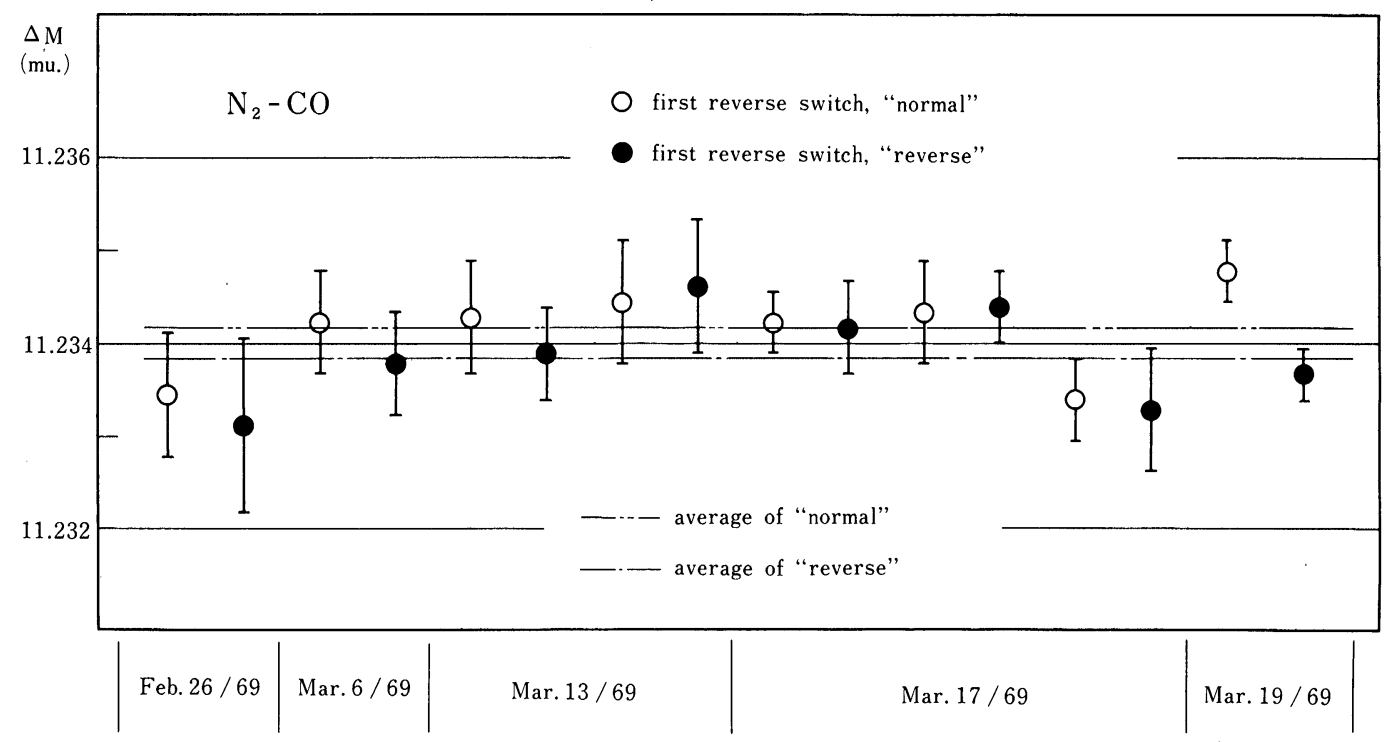

Fig. 13. Mass differences measured with the first reversing operation.

Afterward, with regard to the cause of the discrepancy above mentioned, it was found that a stray magnetic field was produced by the exciting of the homemade relay coil in the matching circuit which was placed in the vicinity of the energy selector. In such a case, only the ion beam of a higher mass member of the doublet may suffer to the deflecting force by such a field at "normal" setting, and, on the other hand, only the low mass ion beam at "reverse" setting, Therefore, values of mass difference obtained at both settings may be deviated to the opposite direction with each other by the same amount. In order to confirm such a fact, the exciting current through the relay coil, i.e. the direction of deflecting force, was reversed. This resulted in the inversion of the behaviour of plots shown in Fig. 12. At last, the pannel of the peak matching circuit was kept away from the ion trajectory. The results thus obtained are the May 15 ' 68 measurements shown at the right side of Fig. 12, and still a small discrepancy remains which is estimated to be about $1.3 \mu u$ on the average and to be about four parts in $10^{8}$ in terms of $\beta$.

In the construction of the present matching circuit, the magnetic shield against the relay coil was performed effectively as much as possible. The same checking measurements were carried out, and the results obtained are shown in Fig. 13. The averaging values of the mass differences measured with "normal" and "reverse" settings, as seen in Fig. 13, indicate that the resultant discrepancy is a little reduced compared with the previous case, and the amount is estimated to be about 0.3 $\mu u$ and is within the statistical deviation of each mass difference measured. By 
the improvement above mentioned, the partial disagreement, $\beta=\delta(\Delta M) / M$, can be reduced to about one part in $10^{8}$. It is noted that the tendency of the deviation in Fig. 13 becomes to be contrary to the case in Fig. 12 and, however, any longer the inversion of the tendency does not occured, even if the exciting current through the relay coil is reversed. The reduced discrepancy corresponds to a certain contact potential of about $10 \mu \mathrm{V}$, or a contact resistance of about $10 \mathrm{~m} \Omega$. A possible difference of contact resistances existing in both sides of relay contact was measured and estimated to be less than $10 \mathrm{~m} \Omega$.

\section{second reversing operation}

The possible thermal and contact potential, which may exist, in $\Delta R$, will give cause a fractional effect to the measured resistance ratio. Such an effect can be reversed with a suitable re- versing of the components and the leads of $\Delta R$, and, also, a reversing of the direction of the current through $\Delta R$ may be effective. In fact, the latter operation was adopted in the present mass difference measurement. This reversing can be well realized by means of the interchanges of the positive terminal and the negative one at the input and the output of the matching circuit The combined switches for this reversing are shown as the second reverse switch in Fig. 9. In such a way, not only the effect just above mentioned but also both effects of the relay contact potential which can be reversed with the first reversing operation and of a certain e. $m$. $f$. in the bleeder $\mathrm{R}$ which is suggested to be negligible may be reversed. The results obtained are shown in Fig. 14. "Normal" denoted in the figure is the case that the portions of the switching relay and $\Delta \mathrm{R}$ are placed at the

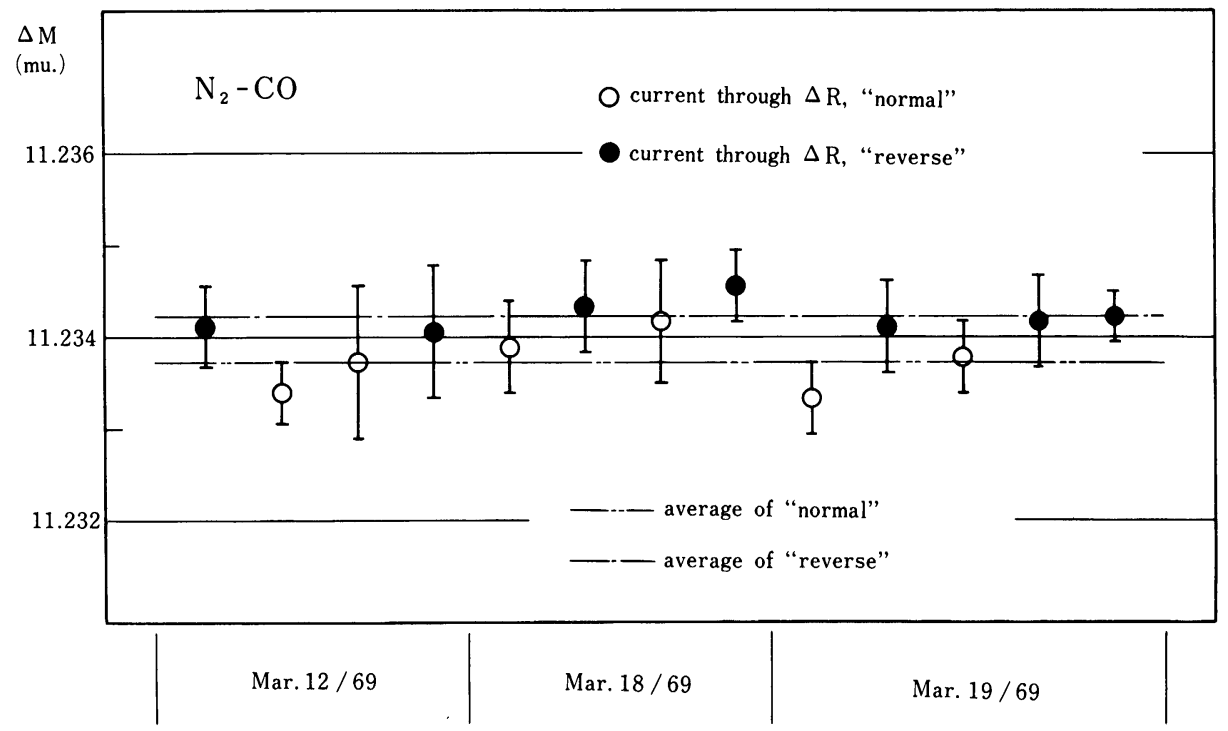

Fig. 14. Mass differences measured with the second reversing operation 
Mass Differences; $\left(\mathrm{C}_{2} \mathrm{H}_{4}-\mathrm{CO}\right),\left(\mathrm{C}_{2} \mathrm{H}_{4}-\mathrm{N}_{2}\right),\left(\mathrm{N}_{2}-\mathrm{CO}\right)$ and $\left(\mathrm{C}_{2} \mathrm{H}_{4}-\mathrm{C}_{2} \mathrm{D}_{2}\right)$
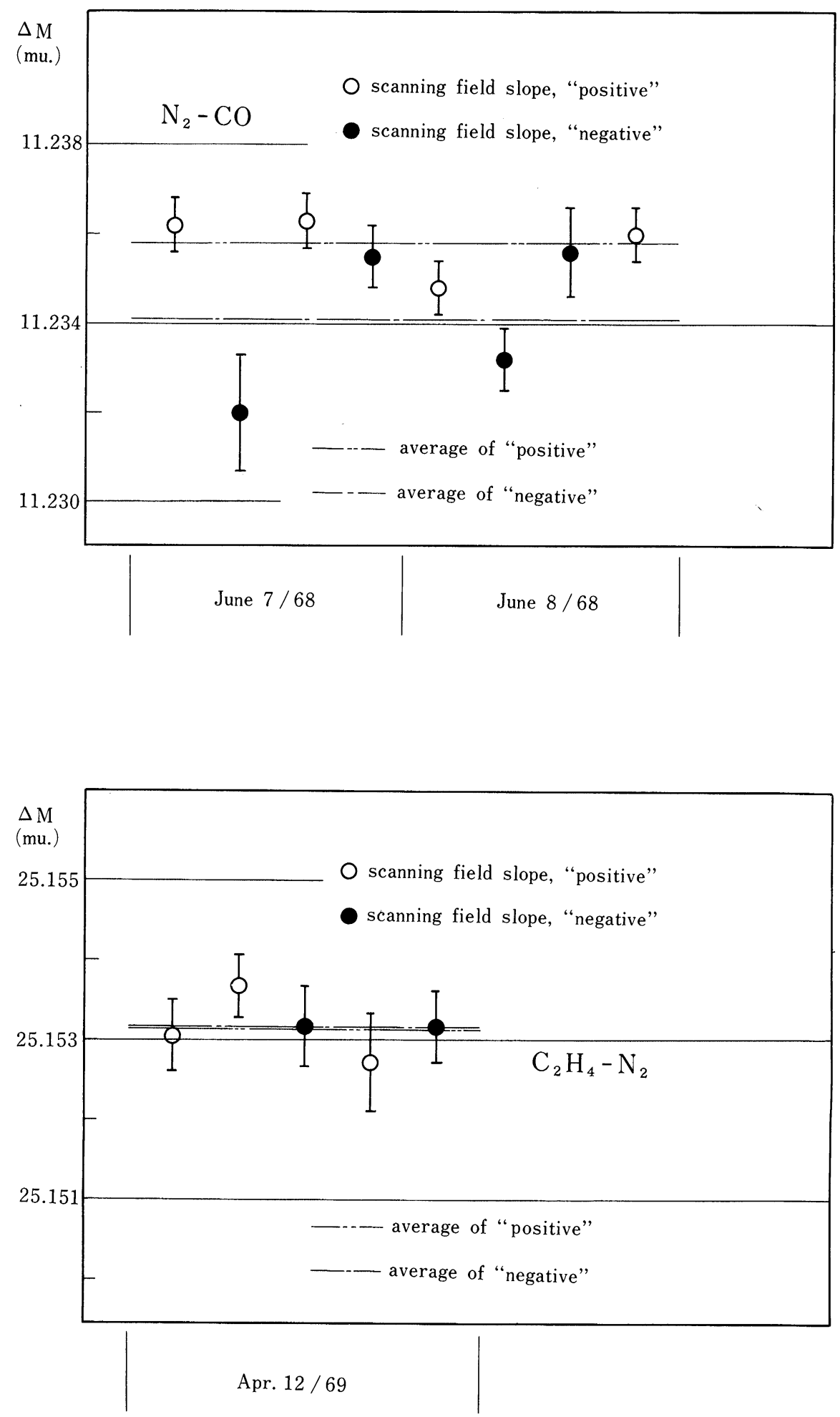

Fig. 15. Mass differences measured with the third reversing operation 
H. Nakabushi, I. Katakuse and K. Ogata

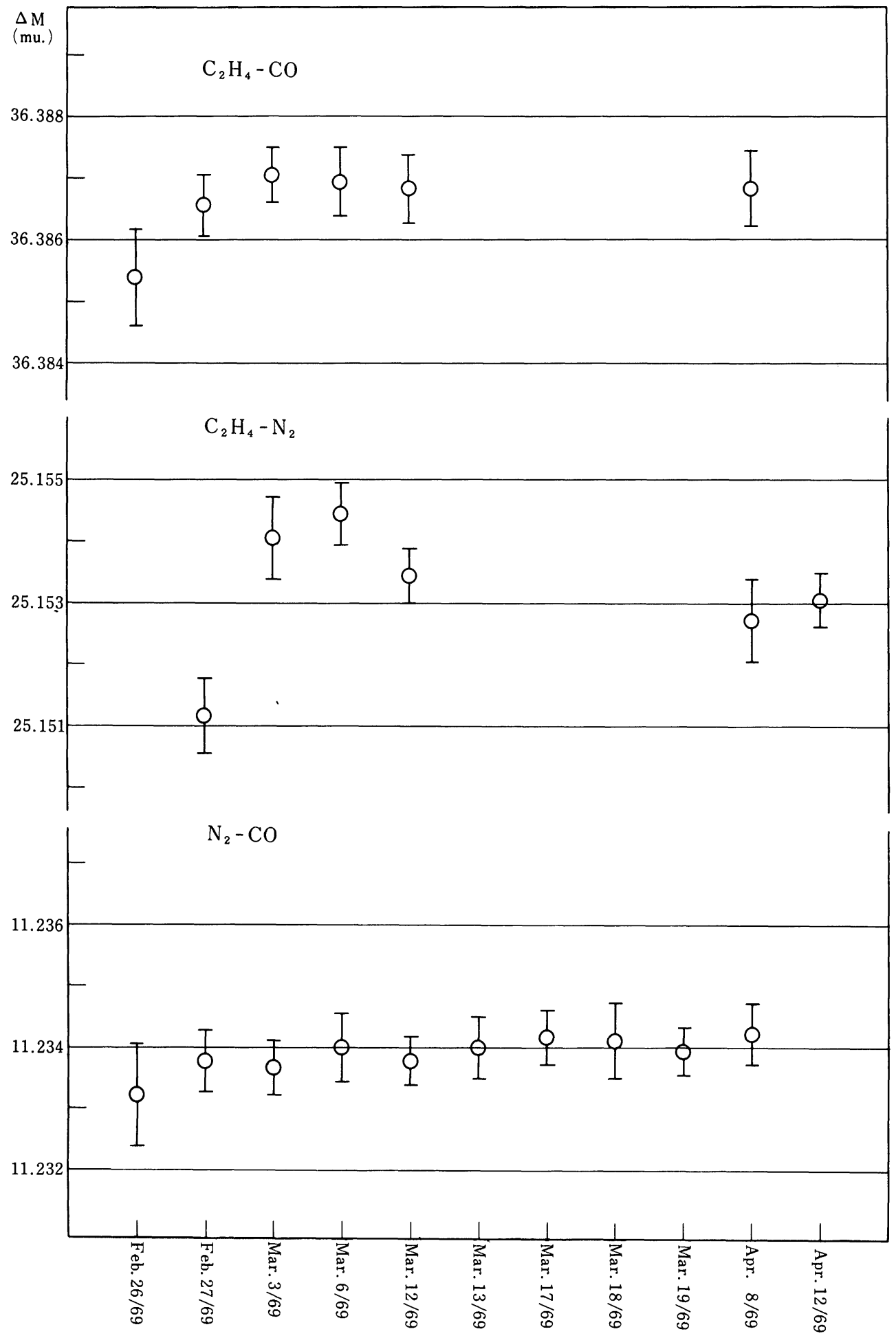

Fig. 16. Reproducibility of the measured mass differences 
Mass Differences; $\left(\mathrm{C}_{2} \mathrm{H}_{4}-\mathrm{CO}\right),\left(\mathrm{C}_{2} \mathrm{H}_{4}-\mathrm{N}_{2}\right),\left(\mathrm{N}_{2}-\mathrm{CO}\right)$ and $\left(\mathrm{C}_{2} \mathrm{H}_{4}-\mathrm{C}_{2} \mathrm{D}_{2}\right)$

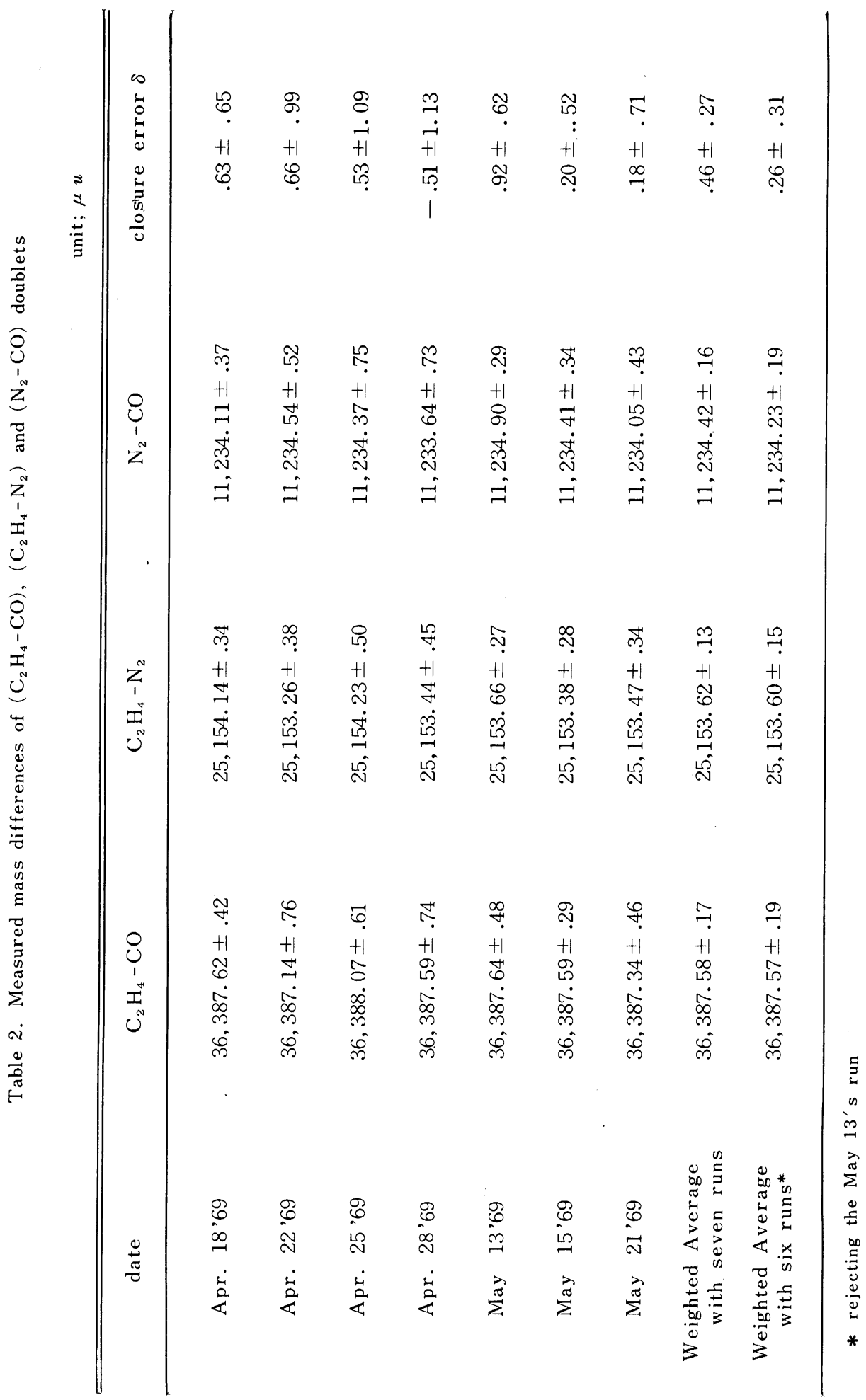




\section{H. Nakabushi, I. Katakuse and K. Ogata}

positive side of the voltage and "reverse" at the negative side. The average values of respective of "normal" and "reverse" plots indicate that the resultant discrepancy is estimated to be about $0.6 \mu u$ and is within the statistical deviation of each measured mass difference. The amount corresponds to the fractional disagreement of about two parts in $10^{8}$ and to a certain e.m. f. of about $20 \mu \mathrm{V}$.

\section{third reversing operation of scan- ning field slope}

The possible mismatchs indebted to the asymmetry of mass peak shape and etc. were checked with reversing of the scanning field slope, $i$. e. either a linear increase or decrease in field. With checking using the previous voltage to current-convertor in which the timing of zero field was not finely adjustable, the discrepancy was observed as is shown in the upper of Fig. 15. It is difficult to suppose whether the cause of such a discrepancy is due to either the asymmetry of peak shape, the matching at the non-zero scanning field or the personal judgement. But it is first of all supposed that the peak matching at the non-zero field may not be better.

As already mentioned, the voltage to current convertor was modified so as to make a fine adjustment of the timing of zero scanning field as much as possible. Then, the same checking was done, and the results obtained are shown in the lower of Fig. 15, in which any discrepancy is not found. Yet, it is not appropriate to conclude that the discrepancy above mentioned is eliminated, because any discrepancy due to the peak shape asymmetry or personal effect in the visual peak matching may appear at the measurements on different day or in different performance of the instrument.

The systematic discrepancies in Fig. 13, 14 and 15 are not so serious in the present case, because these amounts are within the statistical deviation associated with the measurements. However, it is not reasonable to regard such discrepancies as quite negligible ones with above mentioned reason. So, as later mentioned, their reversing operations should be included in the mass difference measurement in order to compensate such discrepancies. In addition, as is later discussed, the closure error of three doublets of the triplet $\left(\mathrm{C}_{2} \mathrm{H}_{4}\right.$ $\mathrm{N}_{2}-\mathrm{CO}$ ) may be valuable for the evaluation of the correction factor $\beta$.

Lastly, for checking the consistency between the daily values of . mass differences measured, the average values of each day's results of $\left(\mathrm{C}_{2} \mathrm{H}_{4}-\mathrm{CO}\right)$, $\left(\mathrm{C}_{2} \mathrm{H}_{4}-\mathrm{N}_{2}\right)$ and $\left(\mathrm{N}_{2}-\mathrm{CO}\right)$ doublet measured during about three months are shown in Fig.16. As is seen in the figure, the reproducibility of the present mass difference measurements is estimated to be less than one part in $10^{7}$.

\subsection{Measurement of doublet mass dif- ferences of $\left(\mathrm{C}_{2} \mathrm{H}_{4}-\mathrm{CO}\right),\left(\mathrm{C}_{2} \mathrm{H}_{4}-\mathrm{N}_{2}\right)$, $\left(\mathrm{N}_{2}-\mathrm{CO}\right)$ and $\left(\mathrm{C}_{2} \mathrm{H}_{4}-\mathrm{C}_{2} \mathrm{D}_{2}\right)$}

As mentioned above, the stability of the operating condition and the reproducibility of the measured result have been considerably improved compared with the previous case, especially by adopting of the emission stabilizer and by improving of the filament support. Thus, before the measurement or the run, little difficulty was experienced to tun up the operating conditions of the instrument. But, some checkings in regard to the performances were as a 
Mass Differences; $\left(\mathrm{C}_{2} \mathrm{H}_{4}-\mathrm{CO}\right),\left(\mathrm{C}_{2} \mathrm{H}_{4}-\mathrm{N}_{2}\right),\left(\mathrm{N}_{2}-\mathrm{CO}\right)$ and $\left(\mathrm{C}_{2} \mathrm{H}_{4}-\mathrm{C}_{2} \mathrm{D}_{2}\right)$

rule performed. A direction focusing and a energy one or their lacks were checked such as described in the previous report, ${ }^{6)}$ before the measurement or the run. In particular, the latter focusing was strictly checked and adjusted if necessary. The half-width resolution of $300,000 \sim 400,000$ is obtained in the present routine measurements, with about $0.01 \mathrm{~mm}$ slit widths of both main and detector slits.

After tuning up and checking of the focusing, the run is started. The run consists of individual settings of $\Delta R$ under sixteen permutations possible with the four different reversing techniques. Three of the reversings are ones used for $\beta$-check. The four different reversing operations are as follows. First, the high mass peak can be observed under all switching relays either exciting or not, with the first reverse switch. Second, the input connection and the output one of the peak matching circuit can simultaneously be reversed in polarity, with the second reverse switch. Third, the scanning field can be a linear increase or decrease, with the third reverse switch. Fourth, the peak matching can be done in increasing or decreasing the value of $\Delta R$.

At first, the measurement of the mass differences of three doublet pairs of the triplet $\left(\mathrm{C}_{2} \mathrm{H}_{4}-\mathrm{N}_{2}-\mathrm{CO}\right)$ was carried out. One run measurement of each doublet was done in one day, and seven runs was taken during about two months. The results thus obtained are tabulated in Table 2. The measured values tabulated are calculated with the following relation;

$$
\Delta M^{\prime}=M \cdot \frac{1}{(50)^{2}} \cdot \frac{\Delta R}{R_{\text {para }}}
$$

The arithmetic mean of sixteen measurements is taken as the value for each run and the quoted error is a statistical standard error of the mean. In fifth column, the closure errors of the triplet closed cycle are also tabulated. The closure error is caluculated with "the following relation;

$$
\delta=\Delta M_{\mathrm{N}_{2}-\mathrm{CO}}^{\prime}+\Delta M_{C_{2} \mathrm{H}_{4}-\mathrm{N}_{2}}^{\prime}-\Delta M_{C_{2} \mathrm{H}_{4}-\mathrm{CO}}^{\prime}
$$

The error of the closure error is estimated in terms of the square root of the sum of the squares of the errors attached to the doublet values. Each closure error is within its error, except for the May $13^{\prime} \mathrm{s}$ result.

Table 3. Measured mass difference of $\left(\mathrm{C}_{2} \mathrm{H}_{4}\right.$ -

\begin{tabular}{|c|c|}
\hline date & $\mathrm{C}_{2} \mathrm{H}_{4}-\mathrm{C}_{2} \mathrm{D}_{2}$ \\
\hline June $24 \quad 69$ & $3,096.02 \pm .44$ \\
\hline June $28 \quad 69$ & $3,096.94 \pm .27$ \\
\hline July $1 \quad$ '69 & $3,096.24 \pm .28$ \\
\hline July $2 \quad 69$ & $3,096.12 \pm .28$ \\
\hline July $\quad 3 \quad 69$ & $3,097.31 \pm .35$ \\
\hline $\begin{array}{l}\text { Weighted } \\
\text { Average }\end{array}$ & $3,096.53 \pm .16$ \\
\hline
\end{tabular}
$\mathrm{C}_{2} \mathrm{D}_{2}$ ) doublet

For obtaining the average values of the measured doublet mass differences, the weighted average is adopted, where the inverse square of the statistical standard error of the value of each run is used as the weight. In the lower of Table 2. the results of the weighted averages obtained with seven runs of all and with six runs omitting the May $13^{\prime} \mathrm{s}$ result are present, associated with the error estimations calculated in terms of the internal variation. The closure errors deduced from the values of the weighted averages, as well, are present. The closure error for the results ob- 
Table 4. Correction of the measured mass differences and estimation of the errors

unit; $\mu u$

\begin{tabular}{|c|c|c|c|c|c|c|c|}
\hline $\begin{array}{l}\text { Measured } \\
\text { Doublet }\end{array}$ & $\begin{array}{l}\text { Measured Value } \\
\Delta M^{\prime}=(\Delta R / R) \cdot M\end{array}$ & $\begin{array}{c}\alpha-\text { correction } \\
\Delta M^{\prime} \cdot \alpha\end{array}$ & $\begin{array}{c}\beta \text {-correction } \\
M \cdot \beta\end{array}$ & $\begin{array}{c}\text { Final Value } \\
\Delta M=(1+\alpha)(\Delta R / R) M \\
+M \beta\end{array}$ & $\begin{array}{l}\text { Statistical } \\
\text { Standard } \\
\text { Error }\end{array}$ & $\begin{array}{l}\text { Resistance } \\
\text { Caribration } \\
\text { Uncertainty }\end{array}$ & $\begin{array}{l}\text { Final } \\
\text { Error }\end{array}$ \\
\hline $\mathrm{C}_{2} \mathrm{H}_{4}-\mathrm{CO}$ & $36,387.57$ & -1.30 & -.26 & $36,386.01$ & .19 & .15 & .24 \\
\hline $\mathrm{C}_{2} \mathrm{H}_{4}-\mathrm{N}_{2}$ & $25,153.60$ & -.90 & -.26 & $25,152.44$ & .15 & .13 & .19 \\
\hline $\mathrm{N}_{2}-\mathrm{CO}$ & $11,234.23$ & -.40 & -.26 & $11,233.57$ & .19 & .08 & .20 \\
\hline $\mathrm{C}_{2} \mathrm{H}_{4}-\mathrm{C}_{2} \mathrm{D}_{2}$ & $3,096.53$ & -.11 & -.26 & $3,096.16$ & .16 & .01 & .16 \\
\hline
\end{tabular}

Table 5. Comparison of the present results with the previous ones

unit; $\mu u$

\begin{tabular}{|c|c|c|c|c|c|c|}
\hline \multicolumn{2}{|l|}{ reference } & \multirow{2}{*}{$\frac{\mathrm{C}_{2} \mathrm{H}_{4}-\mathrm{CO}}{36,383.2 \pm 1.1}$} & \multirow{2}{*}{$\frac{\mathrm{C}_{2} \mathrm{H}_{4}-\mathrm{N}_{2}}{25,154.9 \pm 2.3}$} & $\mathrm{~N}_{2}-\mathrm{CO}$ & \multicolumn{2}{|l|}{$\mathrm{H}_{2}-\mathrm{D}$} \\
\hline Ogata and Matsumoto & $(11)$ & & & $11,227.4 \pm 1.1$ & \multicolumn{2}{|c|}{$1,553.1 \pm 10.3$} \\
\hline Mattauch, Thiele and Wa & a $(2)$ & $36,385.72 \pm .20$ & $25,151.96 \pm .26$ & $11,233.76 \pm .24$ & $1,548.16 \pm$ & .14 \\
\hline Moreland and Bainbridge & $(12)$ & & & & $1,547.77 \pm$ & .14 \\
\hline Stevens and Moreland & $(4)$ & & & & $1,548.07 \pm$ & .08 \\
\hline Johnson et al. & $(5)$ & & & . & $1,548.22 \pm$ & .05 \\
\hline present & & $36,386.01 \pm .24$ & $25,152.44 \pm .19$ & $11,233.57 \pm .20$ & $1,548.08 \pm$ & .08 \\
\hline
\end{tabular}


tained with seven runs is deviated beyond the associated error. This defect may be mainly ascribed to the May $13^{\prime} \mathrm{s}$ result, whose closure error is much deviated beyond the associated error. It may be suggested that the May $13^{\prime}$ s result is responsible to a certain system. atic error, in particular the measurem ment of $\left(\mathrm{N}_{2}-\mathrm{CO}\right)$ mass difference. Accordingly, it may be likely to have reason to reject the May $13^{\prime} \mathrm{s}$ result. In the weighted results obtained after rejecting the May 13's result, the weighted value of mass difference $\left(\mathrm{N}_{2}-\mathrm{CO}\right)$ is lowered by about $0.2 \mu u$ and other two values recieve little change. As the result, theclosure error thus obtained is satisfactory within the associated error. Consequently, as the final measured values not including any correction, the weighted averages obtained with six runs rejjecting the May 13's result are taken.

The mass difference of $\left(\mathrm{C}_{2} \mathrm{H}_{4}\right.$ $\mathrm{C}_{2} \mathrm{D}_{2}$ ) doublet was then measured. In Fig. 17 is shown the mass spectra including above doublet, obtained with the wide scanning. Five runs were taken and the results are tabulated in Table 3 .

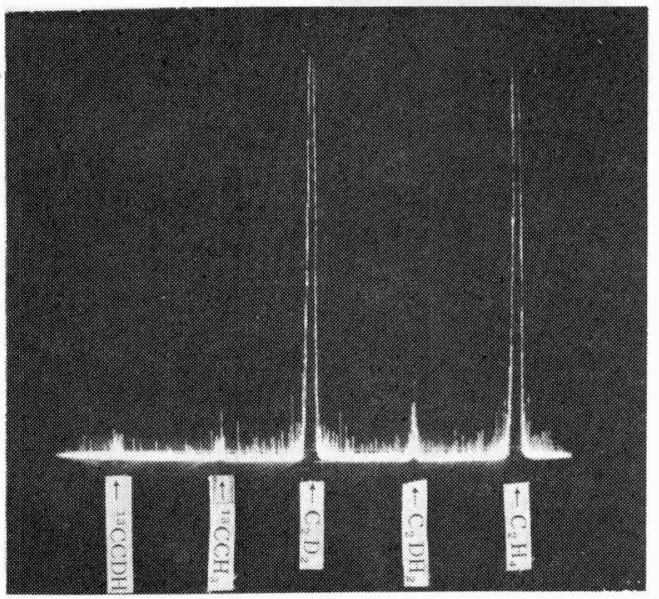

Fig. 17. Mass spectra; ${ }^{13} \mathrm{CCDH}^{-13} \mathrm{CCH}_{3}-\mathrm{C}_{2} \mathrm{D}_{2}$ $\mathrm{C}_{2} \mathrm{DH}_{2}-\mathrm{C}_{2} \mathrm{H}_{4}$

\section{Conclusion}

In the present work, the following relation is adopted for calculating the fractional mass differences of doublets. The relation includes the correction factors already mentioned,

$$
\frac{\Delta M}{M}=(1+\alpha) \frac{1}{(50)^{2}} \cdot \frac{\Delta R}{R_{\text {para }}}+\beta
$$

or

$$
\Delta M=(1+\alpha) \cdot M \cdot \frac{1}{(50)^{2}} \quad \frac{\Delta R}{R_{\text {para }}}+M \cdot \beta .(9)
$$

In the preceding section, the measured values of each doublet calculated by Eq. 7 are shown. For evaluating the amount of $\alpha$-correction, one hydrogen mass difference of the doublet ( $\mathrm{COH}-\mathrm{CO})$ was measured, and $1+\alpha=0.999964$ was obtained. The amount of $\alpha$ is estimated to be $-3.6 \times 10^{-5}$, and the $\alpha$-correction thus obtained is applied to each measured value of doublet mass difference in terms of $\Delta M \cdot \alpha$. The effects of $\beta$-term are expected to be eliminated with the various reversing techniques adopted in the run measurement. On the other hand, by the zero cycle checking of the triplet $\left(\mathrm{C}_{2} \mathrm{H}_{4}-\mathrm{N}_{2}-\mathrm{CO}\right)$, the final closure error is estimated to be +0.26 $\mu u$ in the present work. And, the closure error is taken into account for determining the final doublet mass differences.

Customarily, a least squares adjusment is applied to correct the closure error of the triplet closed cycle. In such case, it is necessary that the errors are statistically distributed. However, taking a sight of the closure error of each day result in Table 2, each closure error is deviated in the positive side, except for the Apr. 28's error. Accordingly, it is not probably adequate to 


\section{H. Nakabushi, I. Katakuse and K. Ogata}

consider that each closure error is statistically distributed, and it may not be to treat the measured values with the least squares. In the present work, the expected systematic errors are considered, and their effects are eliminated as much as possible or the amounts of the errors are estimated. But, certain unknownable systematic errors may yet remain, and the closure excess found for $\left(\mathrm{C}_{2} \mathrm{H}_{4}-\mathrm{N}_{2}-\mathrm{CO}\right)$ zero cycle suggests this possibility. This excess may be included in $\beta$-term of Eq. 9, and not in $\alpha$-term. As above mentioned, the effect caused by $\beta$ has the same influence on $\Delta M$, independent of the magnitude of $\Delta M$. The closure error $\delta$ of Eq. 8 may be expressed in terms of $\delta=-M \cdot \beta$, where $M=28 u$ in the present case. $\beta$ is estimated to be about one part in $10^{8}$ for the evaluated closure excess of $\delta=$ $0.26 \mu u$.

Thus, it might be suggested that each measured mass difference value uniformly deviates in a little larger side than its true value. In order to find out the cause of such systematic error, the further and more detail investigations have to be performed. For the measured $\left(\mathrm{C}_{2} \mathrm{H}_{4}-\mathrm{C}_{2} \mathrm{D}_{2}\right)$ doublet mass difference, the same kind of systematic error may be existing. In the present work, the zero checking including this doublet, as in the case of the triplet $\left(\mathrm{C}_{2} \mathrm{H}_{4}-\mathrm{N}_{2}-\mathrm{CO}\right)$, has not yet done. So, assuming the same amount of $\beta$-correction available for the measured $\left(\mathrm{C}_{2} \mathrm{H}_{4}-\mathrm{C}_{2} \mathrm{D}_{2}\right)$ mass difference, the final value is corrected. The mass difference value of $\left(\mathrm{C}_{2} \mathrm{H}_{4}-\mathrm{C}_{2} \mathrm{D}_{2}\right)$ doublet, thus obtained, may be tentative one by just above mentioned reason. In Table 4 , the estimated values of $\alpha-$ and $\beta$ corrections and the final corrected values of the measured doublet mass differences are shown.

In Table 4, the error of the final value are also estimated. The final error is calculated in terms of the square root of the sum of the squares of the statistical standard error and the resistance calibration uncertainty. Each statistical standard error is one attached to the weighted average obtained with six runs in Table 2. The resistance calibration uncertainty of each measured value of $\Delta \mathrm{R}$ is obtained with such procedure as mentioned in the 3-1 section. As the result, the uncertainties of the measured $\Delta \mathrm{R}$ are estimated to be about $27 \mathrm{~m} \Omega$, $22 m \Omega, 14 m \Omega$ and $2 m \Omega$ for the measured doublets $\left(\mathrm{C}_{2} \mathrm{H}_{4}-\mathrm{CO}\right),\left(\mathrm{C}_{2} \mathrm{H}_{4}-\mathrm{N}_{2}\right)$, $\left(\mathrm{N}_{2}-\mathrm{CO}\right)$ and $\left(\mathrm{C}_{2} \mathrm{H}_{4}-\mathrm{C}_{2} \mathrm{D}_{2}\right)$, respectively. Their amounts are reduced to the corresponding mass values, which are shown in the table.

The mass difference values thus determined in the present work are compared with the other previous results in Table 5 .

\section{References}

1) F. Everling, L. A. König, J. H. E. Mattauch and A. H. Wapstra, Nucl. Phys., 25, 177, (1961).

2) J.H. E. Mattauch, W. Thiele and A. H. Wapstra, Nucl. Phys., 67, 1, (1965).

3) J. L. Benson and W. H. Johnson, Jr., Phys. Rev., 141, 1112, (1966).

4) C. M. Stevens and P. E. Moreland, Proc. Int. Conf. "Atomic Masses", p. 673, Winnipeg, (1967).

$5)$ W. H. Johnson, M. C. Hudson, R. A. Britten and D. C. Kayper, ibid. p. 793.

$6)$ I. Katakuse, H. Nakabushi, T. Asano, S. Matsumoto and K. Ogata, Mass Spectroscopy, 16, 379, (1968).

$7)$ S. Matsumoto, Thesis, Faculty of Science, Osaka Univ., (1969).

8 ) S. Matsumoto, Mass Spectroscopy, 17, 474, (1969).

9) to be published in this issue 
Mass Differences; $\left(\mathrm{C}_{2} \mathrm{H}_{4}-\mathrm{CO}\right),\left(\mathrm{C}_{2} \mathrm{H}_{4}-\mathrm{N}_{2}\right),\left(\mathrm{N}_{2}-\mathrm{CO}\right)$ and $\left(\mathrm{C}_{2} \mathrm{H}_{4}-\mathrm{C}_{2} \mathrm{D}_{2}\right)$

10) A. O. C. Nier, Proc. Int. Conf. "Nuclear Masses and their Determination",

p. 185, (1957).

11) K. Ogata and S. Matsumoto, Proc. Int.
Conf. “Nuclidic Masses", p. 415, Vienna, (1963).

12) P. E. Moreland and K. T. Bainbridge, ibid. p. 423. 